\title{
Article
}

\section{The Arabidopsis TETRATRICOPEPTIDE THIOREDOXIN-LIKE 1 Gene Is Involved in Anisotropic Root Growth during Osmotic Stress Adaptation}

\author{
María Belén Cuadrado-Pedetti ${ }^{1}{ }^{\mathbb{D}}$, Inés Rauschert ${ }^{2}$, María Martha Sainz ${ }^{1}{ }^{\mathbb{D}}$, Vítor Amorim-Silva ${ }^{3}$, \\ Miguel Angel Botella ${ }^{3}$, Omar Borsani ${ }^{1}$ and Mariana Sotelo-Silveira ${ }^{1, * \mathbb{D}}$ \\ 1 Laboratorio de Bioquímica, Departamento de Biología Vegetal, Facultad de Agronomía, UdelaR, \\ 12900 Montevideo, Uruguay; belencuadrado1994@gmail.com (M.B.C.-P.); msainz@fagro.edu.uy (M.M.S.); \\ oborsani@fagro.edu.uy (O.B.) \\ 2 Laboratorio de Señalización Celular y Nanobiología, Instituto de Investigaciones Biológicas Clemente \\ Estable (IIBCE), 11600 Montevideo, Uruguay; irauschert@iibce.edu.uy \\ 3 Departamento de Biología Molecular y Bioquímica, Instituto de Hortifruticultura Subtropical y Mediterránea \\ "La Mayora," Universidad de Málaga-Consejo Superior de Investigaciones Científicas (IHSM-UMA-CSIC), \\ Universidad de Málaga, Campus Teatinos, 29071 Málaga, Spain; vitoramorimsilva@uma.es (V.A.-S); \\ mabotella@uma.es (M.A.B.) \\ * Correspondence: msotelo@fagro.edu.uy
}

\section{check for} updates

Citation: Cuadrado-Pedetti, M.B.; Rauschert, I.; Sainz, M.M.;

Amorim-Silva, V.; Botella, M.A.; Borsani, O.; Sotelo-Silveira, M. The Arabidopsis TETRATRICOPEPTIDE THIOREDOXIN-LIKE 1 Gene Is Involved in Anisotropic Root Growth during Osmotic Stress Adaptation. Genes 2021, 12, 236. https://doi.org/ $10.3390 /$ genes 12020236

Academic Editor: Ignacio Ezquer, Paola Vittorioso and Stefan de Folter Received: 23 December 2020

Accepted: 2 February 2021

Published: 7 February 2021

Publisher's Note: MDPI stays neutral with regard to jurisdictional claims in published maps and institutional affiliations.

Copyright: (c) 2021 by the authors. Licensee MDPI, Basel, Switzerland. This article is an open access article distributed under the terms and conditions of the Creative Commons Attribution (CC BY) license (https:// creativecommons.org/licenses/by/ $4.0 /)$.

\begin{abstract}
Mutations in the Arabidopsis TETRATRICOPEPTIDE THIOREDOXIN-LIKE 1 (TTL1) gene cause reduced tolerance to osmotic stress evidenced by an arrest in root growth and root swelling, which makes it an interesting model to explore how root growth is controlled under stress conditions. We found that osmotic stress reduced the growth rate of the primary root by inhibiting the cell elongation in the elongation zone followed by a reduction in the number of cortical cells in the proximal meristem. We then studied the stiffness of epidermal cell walls in the root elongation zone of $t t l 1$ mutants under osmotic stress using atomic force microscopy. In plants grown in control conditions, the mean apparent elastic modulus was $448 \%$ higher for live Col- 0 cell walls than for $t t l 1$ $(88.1 \pm 2.8$ vs. $16.08 \pm 6.9 \mathrm{kPa})$. Seven days of osmotic stress caused an increase in the stiffness in the cell wall of the cells from the elongation zone of $87 \%$ and $84 \%$ for Col- 0 and $t t l 1$, respectively. These findings suggest that TTL1 may play a role controlling cell expansion orientation during root growth, necessary for osmotic stress adaptation.
\end{abstract}

Keywords: TTL1; root growth; Arabidopsis; atomic force microscopy

\section{Introduction}

Drought is a significant constraint for crop production worldwide. A critical trait related with water deficit tolerance is the root adaptation capacity to keep growing and exploring the soil in a new hydric condition [1-4]. Even though it is critical for plant survival, root growth adaptation during this stressful condition is not well understood [5].

Arabidopsis primary root growth is directed by a small number of stem cells located in the root apical meristem (RAM) that generate all the cell types of the root from cell division followed by regulated cellular expansion and differentiation [6]. In the longitudinal axes, Arabidopsis primary root is organized in 4 developmental zones: the proximal meristem $(\mathrm{PM})$, the transition zone (TZ), the elongation zone (EZ), and the differentiation zone (DZ) $[7,8]$. The PM extends from the quiescent center (QC) to the first elongated cell; where, isodiametric cells with high mitotic activity began radial expansion defining the root width [8]. In the TZ cells near the PM maintain the mitotic activity while the cells in the distal part develop anisotropic expansion in the longitudinal axis [8]. In the EZ, cells exponentially elongate, with large vacuoles and the nucleus displaced to the cell wall. In this zone, multiple changes occur at the cellular level, such as in microtubules reorientation, 
cellulose deposition, cell wall softening, and new cell wall synthesis [9]. Fully elongated cells are displaced to the DZ where terminally differentiate and no longer elongate $[7,8]$. Root growth reaches a stationary regime that is the result of the delicate balance of cell division, elongation, and differentiation, in which the regulation of the direction and extent of cell wall expansion of EZ cells play a major role [10-12]. In the stationary phase, the sizes of the PM and EZ of the root remain constant and the root grows by increasing the length of the DZ, a process that is in turn dictated by the mature cell length and the cell proliferation rate in the meristem $[7,10]$.

During the past few years, several studies emphasized the role of brassinosteroids (BR) in directing root growth [13-17]. BR deficient mutants have short roots due to less elongated mature cells. Moreover treatments with high BR concentrations inhibited root growth due to a reduction in the size of meristem produced by an acceleration in cellular elongation [17]. In the EZ, BR promotes cell elongation through BRASSINAZOLE-RESISTANT 1 (BZR1) transcription factor activation, and endogenous levels of $B R$ are required to maintain the balance between the meristematic zone and the elongation zone. It was shown that the BZR1 expression pattern and subcellular localization depend on endogenous BR and auxin levels [12], and that auxin distribution is also influenced by the BR content [18], establishing opposed gradients along the root meristem. Besides the opposed distribution gradients of auxins and BR, evidence derived from transcriptomic analysis of root apices showed that they have opposite effects on cellular elongation and the control of genes that co-regulate this process $[12,13,17,18]$. Therefore, the spatiotemporal antagonism between auxins and BR is important to maintain cellular domains of quiescence, division and elongation that lead to an equilibrated root growth rate $[12,19,20]$.

Despite these advances in the understanding of the mechanism of root growth, little is known about how the balance between cell division and elongation leading to root growth is maintained during challenging environmental conditions [21]. It has been shown that the primary root responds to saline stress dynamically; immediately after transfer to hyperosmotic media, the root growth rate drops due to a reduction in turgor pressure [15]. Depending on the stress severity, cells in the elongation zone may enter a quiescent stage before their growth rate is recovered $[15,22]$. The timing of growth recovery was predicted to be regulated by brassinosteroid and gibberellic acid signaling pathways that regulate genes involved in cell wall synthesis [15,22]. At the cellular level, growth is regulated by turgor pressure and the rate of cell wall loosening. Under hyperosmotic stress, root epidermal and cortex cells swell [23] similar to that observed with genetic or chemical disruption of cell wall organization [24-28]. Likewise, mutants impaired in cell wall organization/integrity are hypersensitive to osmotic/ionic stress [22,29,30]. At the organ level, hyperosmotic stress inhibits root cell proliferation and elongation [23].

Mutation in the Arabidopsis TETRATRICOPEPTIDE THIOREDOXIN-LIKE 1 (TTL1) gene cause root swelling and root growth arrest under $\mathrm{NaCl}$ and osmotic stress [31-33]. TTL genes encode a novel Arabidopsis family of proteins specific to land plants that have six tetratricopeptide repeat (TPR) domains located in specific positions of the sequence and a sequence with homology to thioredoxins in C-terminal position [31,32]. TPR domains are well-described protein-protein interaction modules. Recently, Amorim-Silva et al., 2019 showed interaction between TTL3 and constitutively active BRI1, BSU1, and BZR1. Moreover TTL3 has been associated in vivo with most BR signaling components except for BRI1-ASSOCIATED KINASE1 (BAK1). TTL3 showed dual cytoplasmic and membrane localization dependent on endogenous BR content suggesting that TTL proteins may function as positive regulators of BR signaling [33]. In this work we investigated the role of TTL1 in primary root growth in osmotic stress conditions. We aimed to understand if the swelling phenotype observed in osmotic stress conditions is due to the involvement of TTL1 in the maintenance of the physical properties of the cell wall during the anisotropic cell expansion process that contributes to the final organ size.

We show that a mutation in TTL1 caused a deceleration in root growth rate compared to Col-0 with increasing osmotic potential. Moreover, osmotic stress caused both a specific 
inhibition in the elongation of cells in EZ as well as a reduction in the number of cortical cells in the PM.

Atomic force indentation experiments showed that the cell wall of cells in the EZ of $t t l 1$ were more elastic than those of Col-0 even in control conditions. Under osmotic stress, both the cell wall of the elongation zone cells of Col- 0 and those of $t t l 1$ became stiffer, but $t t l 1$ cell walls did not reach the magnitude of stiffness of Col- 0 cells walls. These data together with the reduction in cell elongation and proliferation observed in the $t t l 1$ mutant under osmotic stress support a role for TTL1 in maintaining cell wall physical properties necessary for sustaining a proper root growth during osmotic stress.

\section{Materials and Methods}

\subsection{Plant Material and Growth Conditions}

We used the original T-DNA insertion lines Salk_063943 (for TTL1; AT1G53300) that is in the Columbia-0 (Col-0) wild-type background. $t$ tl1, pTTL1::GUS and the Procuste1 (prc1-1) mutant, which consist in a knock-out mutation (Q720stop) in the CESA6 gene (AT5G64740), and was previously described in [34,35]. 35S::BZR1::YFP seeds [17] were kindly provided by Zhi-Yong Wang.

The seeds were surface sterilized with $70 \%(v / v)$ ethanol for $7 \mathrm{~min}$, followed by $20 \%$ sodium hypochlorite for $7 \mathrm{~min}$, and washed three times with sterile water. Seeds were stratified at $4{ }^{\circ} \mathrm{C}$ in the dark for $4 \mathrm{~d}$ and plated onto petri dishes containing basal Murashige and Skoog (MS) medium [36] + sucrose $1.5 \%$, for in vitro germination Plates were placed in a long-day regime ( $16 \mathrm{~h}$ of light $/ 8 \mathrm{~h}$ of dark) with $25 \mu \mathrm{mol} \mathrm{m}{ }^{2} \mathrm{~s}^{-1}$ light intensity and $23^{\circ} \mathrm{C}$ (day/night).

\subsection{Osmotic Stress Treatment}

Seedlings were grown $5 \mathrm{~d}$ in basal MS $+1.5 \%$ sucrose medium ( $-0.4 \mathrm{MPa})$ and then transferred to petri dishes containing basal MS $+1.5 \%$ sucrose supplemented with $300 \mathrm{mM}$ mannitol $(-0.7 \mathrm{MPa})$ or $400 \mathrm{mM}$ mannitol $(-1.2 \mathrm{MPa})$. Osmotic potential was estimated by cryoscopic osmometer model OSMOMAT 030 (Gonotech, Berlin, Germany). Seedling were grown under stress conditions for 7 days, unless stated otherwise.

\subsection{Polymerase Chain Reaction (PCR)-Based Genotyping}

Identification of the $t t l 1$ allele was undertaken using the following primers: LBSALK (5'-TGG TTC ACG TAG TGG GCC ATC G-3'); TTL1DPCRF (5'-TGG ACT CAC CACCACCAC TA-3') and TTL1DPCRR (5'-ACC GAG TCT GCG AAC AAG AT-3')

\subsection{Epibrasinolide and Propiconazole Sensitivity Assay}

To test root growth inhibition by epibrasinolide (BL) and propiconazole (PCZ) seedlings were germinated in basal medium (MS $+1.5 \%$ sucrose) as described previously. After 5 days of growth in vertical plates, the seedlings were transferred to basal medium supplemented with $0.1 \mu \mathrm{M}$ of BL, $0.2 \mu \mathrm{M}$ BL or $0.5 \mu \mathrm{M}$ PCZ; or hyperosmotic medium (MS $+1.5 \%$ sucrose $+400 \mathrm{mM}$ mannitol) supplemented with $0.1 \mu \mathrm{M}$ of BL, $0.2 \mu \mathrm{M}$ BL or $0.5 \mu \mathrm{M}$ PCZ. After 9 days in each treatment roots were photographed, and root length was measured using Zeizz-ZEN pro Imaging Software (Zeizz, Oberkochen, Germany). Comparisons between genotypes in different treatments were determined by a Student's $t$-test, in all cases a $p<0.05$ was considered significant.

\subsection{GUS Staining Assay}

For GUS analysis, Arabidopsis roots were incubated overnight at $37{ }^{\circ} \mathrm{C}$ with a 5bromo-4-chloro-3-indolyl- $\beta$-glucuronic acid solution (Gold Biotechnology Inc., St. Louis $\mathrm{MO}$, US) plus $1 \mathrm{mM} \mathrm{K}_{3} \mathrm{Fe}(\mathrm{CN})_{6}$ y $1 \mathrm{mM} \mathrm{K}_{4} \mathrm{Fe}(\mathrm{CN})_{6} \cdot 3 \mathrm{H}_{2} \mathrm{O}$. For clearings, tissue was treated overnight with Hoyer's solution [37] plus 20\% lactic acid. Light images from GUS-stained tissues and from roots were obtained using Zeizz Axio Imager M2 microscope (Zeizz, Oberkochen, Germany) equipped with differential interference contrast (Nomarski) optics. 


\subsection{Root Meristem Analysis}

To measure meristem characteristics, we follow the protocol of [38]. Root proximal meristem size was determined by counting the number of cortex cells in a file extending from the QC to the first elongated cell excluded. EZ extended from the first elongated cell till the first hair in the epidermis layer. Mature cell length was measured in the last cell of the EZ. Comparison between the number of cortical cells in the PM and mature cell lengths of Col- 0 and the mutants were determined by a Student's $t$-test, in all cases a $p<0.05$ was considered significant. Images used to measure were taken using Zeizz Axio Imager M2 microscope and processed with Zeizz-ZEN pro Imaging Software.

The root length from plants growing in vertical plates was measured over time from 5 to 10 days after germination; 30 roots of each genotype were measured from the hypocotyl to the root tip. We used "least squares" method to determine the curve of best fit for each root length over time. The root growth rate was calculated from the slope of the regression for each root. The root growth rate of Col-0 and the mutants in each growth condition were determined by a Student's $t$-test, in all cases a $p<0.05$ was considered significant.

An estimate of growth parameters from cortical cell length profiles were calculated as described by [39].
a. Root growth rate: root length at day 8-root length at day 6
b. Cell production rate: a /average mature cell length
c. Length of the cell cycle: number of cortical cells in $\mathrm{PM} / \mathrm{b}$ * $\ln (2)$
d. The average time interval between each cortical cell leaving the meristem to enter the TZ and EZ: $1 / b$
e. Elongation cell rate in the PM: $\frac{1}{2}$ max cell length in PM/c

\subsection{Atomic Force Microscopy (AFM) Nanoindentation Experiments}

Atomic force microscopy (AFM) indentation analysis were conducted with an atomic force microscope (BioScope Catalyst, Bruker, Billerica, MA, USA).

Seedlings were attached to Petri dishes with a thin layer of silicone glue (PEGAMIL, ANAEROBICOS S.R.L., Buenos Aires, Argentina).

The plated seedlings were placed into the optical inverted microscope coupled to the AFM (Olympus IX81, Miami, FL, USA). Roots from 7 days seedlings studied using an AFM fluid cantilever holder at $25^{\circ} \mathrm{C}$. The absence of PI fluorescence was used to confirm the viability of the roots, and only live roots were measured. All AFM measurements were performed within $1 \mathrm{~h}$ after insertion of the AFM head. The silicon nitride probe (DNP-10, cantilever A; Bruker, Billerica, MA, USA), with a tip radius of $20 \mathrm{~nm}$, was attached to a triangular $175-\mu \mathrm{m}$-long cantilever with a spring constant of $0.35 \mathrm{~N} / \mathrm{m}$, following the manufacturer's instructions. For indentation we did as follows: (1) the cantilever was positioned using a $\times 10$ and $\times 20$ magnification eyepiece on the surface of the fourth elongated epidermal cell of the primary root; taking care to position it in the center of the cell. A low $(1 \mathrm{~Hz})$ frequency was set to maximize the number of force curves that were captured, as previously described [40]. At least 150 force curves were captured for each root.

Young's Modulus (AEM) was obtained from first and second-order polynomial fits of the obtained force curves, according to [41].

All force curves were fitted with a second-order polynomial to obtain the Young's Modulus. Force curves with a correlation coefficient lower than 0.99 were discarded. A normalized histogram of the remaining data was created and fitted with a Gaussian distribution. Data points outside the $95 \%$ confidence interval were discarded and both the histogram and the Gaussian fit were recalculated.

All comparisons between groups were determined by a Student's $t$-test, in all cases a $p<0.05$ was considered significant.

Topography images were obtained with MSNL-10/A probe in contact mode. 


\subsection{Epistasis}

For TTL1 and CESA6, we evaluated the level of epistasis by comparing the AEM of $t t l 1 \times$ prc1-1 double mutant with the product of the AEM $t t l 1$ and AEM prc1-1 values of the corresponding single mutants [42] using this formula: $\varepsilon=$ AEM $t t l 1 \times$ prc1-1 - AEM ttl1 AEM prc1-1 [42], in which $\varepsilon=0$ describes no epistasis, $\varepsilon>0$ corresponds to buffering epistasis and $\varepsilon<0$ to aggravating epistasis [42].

\subsection{Confocal Imaging}

Fluorescence signal of 35S::BZR1::YFP and ttl1 35S::BZR1::YFP was observed with confocal microscopy Zeizz LSM 800-AiryScan (Zeizz, Oberkochen, Germany). Exitation was done using a $488 \mathrm{~nm}$ laser, and emission was detected between 505 and $550 \mathrm{~nm}$.

\section{Results}

\subsection{Root Growth Rate Decelerate When Osmotic Potential Increases}

Mutations in the Arabidopsis TTL1 gene cause reduced tolerance to $\mathrm{NaCl}$ and osmotic stress [32]. The main phenotype caused by osmotic stress in $t t l 1$ mutants was swollen root tips and root growth arrest [31-33]; Figure 1C. In this work we aim to investigate the role of TTL1 in maintaining primary root growth during osmotic stress adaptation. For this purpose, we grew Col- 0 and $t t l 1$ seedlings in solid MS $+1.5 \%$ sucrose for the control condition and in solid MS $+1.5 \%$ sucrose containing $300 \mathrm{mM}$ mannitol (corresponding to -0.7 MegaPascal (MPa) of osmotic potential) or $400 \mathrm{mM}$ mannitol (corresponding to $-1.2 \mathrm{MPa}$ of osmotic potential). In control conditions, $t t l 1$ primary root growth rate was not significantly different from that of Col-0 (Figure 1A). Interestingly, root growth rate decelerates and is not arrested with increasing osmotic potential (Figure 1). Col-0 reduced $50 \%$ its root growth rate after growing during 7 days in a medium with $-0.7 \mathrm{MPa}$ of osmotic potential and $88 \%$ when exposed the same period to a medium with $-1.2 \mathrm{MPa}$ of osmotic potential. However, the root growth rate was significantly even more reduced in the $t t l 1$ mutant, $63 \%$ at $-0.7 \mathrm{MPa}$ and $95 \%$ at $1-2 \mathrm{MPa}$ of osmotic potential (Figure $1 \mathrm{~A}$ ).

The root length is dependent on the balance between the rate of cell division and cell elongation. Usually, a high number of cells dividing at the RAM produces more cells that can elongate and differentiate, resulting in a high root growth rate [43]. Growth parameters affecting the root growth rate were determined in the cortical cell files from the stem cell initials near the quiescent center to the beginning of the differentiation zone in roots exposed to 7 days of osmotic stress [38,39].

Although the number of cortical cells in the PM was reduced in both genotypes in response to increasing osmotic potential, the effect was different in Col- 0 and $t t l 1$. The number of cells in the PM in Col- 0 was reduced by $30 \%$ after growing for 7 days at $-0.7 \mathrm{MPa}$ of osmotic potential and by $72 \%$ after 7 days at $-1.2 \mathrm{MPa}$. However, the response of the $t t l 1$ mutant was more severe in both osmotic stress conditions: $t t l 1$ had a reduction of the cell number by $42 \%$ at $-0.7 \mathrm{MPa}$ and by $79 \%$ at $-1.2 \mathrm{MPa}$ compared to Col-0 PM in control conditions (Figure 2).

Osmotic stress also affected the length of mature cells in both genotypes. In the $t t l 1$ mutant $-0.7 \mathrm{MPa}$ caused a strong reduction in the length of mature cells, and a higher osmotic potential of $-1.2 \mathrm{MPa}$ reduced mature cell length an additional 7\% (Figure 2). Interestingly, $-0.7 \mathrm{MPa}$ caused a more severe reduction effect on mature cell length than in the number of cortical cells in the PM compared to control conditions, $16 \%$ and $26 \%$ more in Col-0 and in $t t l 1$, respectively. Moreover, at $-1.2 \mathrm{MPa}$ mature cell length was not significantly different between Col-0 and $t t l 1$ (Figure 2), indicating a mature length threshold to sustain root growth.

Furthermore, at $-1.2 \mathrm{MPa}$, differences were also observed in the time dependence of cell number reduction in the PM. In Col-0 30\% of the reduction occurred in the first 2 days and $65 \%$ after 7 days of exposure (Table S1). $t t l 1$, however, reduced its PM cell number by $70 \%$ in the first 2 days of exposure (Tables S2 and S3) indicating that TTL1 participate in the control of cell proliferation in the first days of stress adaptation. 
The PM cell proliferation rate depends on the cells that are produced in the stem cell niche (SCN), the dividing cells at the PM, and the cells that transit to the EZ. We did not detect any morphological differences in the organization of the PM in $t t l 1$, neither in control nor stress conditions. (Figure 1B). However, under osmotic stress the cells in $t t l 1$ transited more rapidly to the elongation zone and prematurely acquired characteristics of differentiated cells in the epidermis (i.e., root hairs; Figure 1C). In addition, osmotic stress produces a radial expansion in cells of the epidermis and cortex of the TZ and EZ in the $t t l 1$ mutant, an expansion that remains in differentiated cells (Figure 1C).

A cortical cell profile analysis was used to estimate the cell production rate, the length of the cell cycle, the elongation rate in the PM and the average time between each cell entering the TZ and the EZ as described in Materials and Methods. The estimations were made with roots grown in control and $-0.7 \mathrm{MPa}$ of osmotic potential media because at $-1.2 \mathrm{MPa}$ the root growth rate was too low for obtaining reliable data (Figure 3).

A

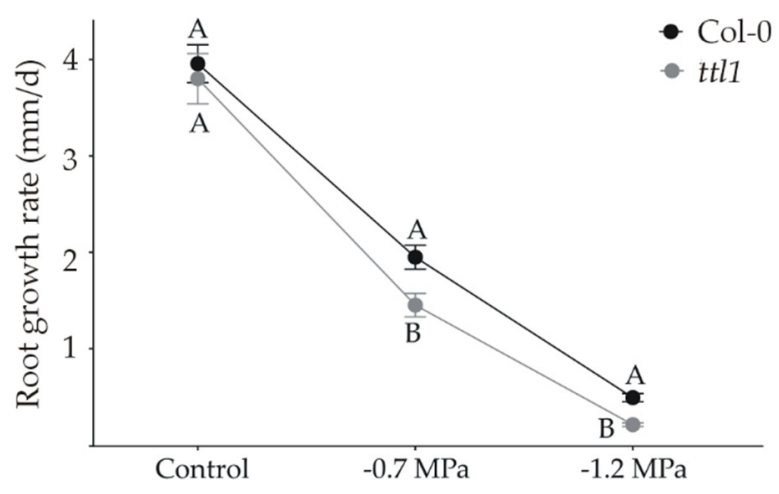

B

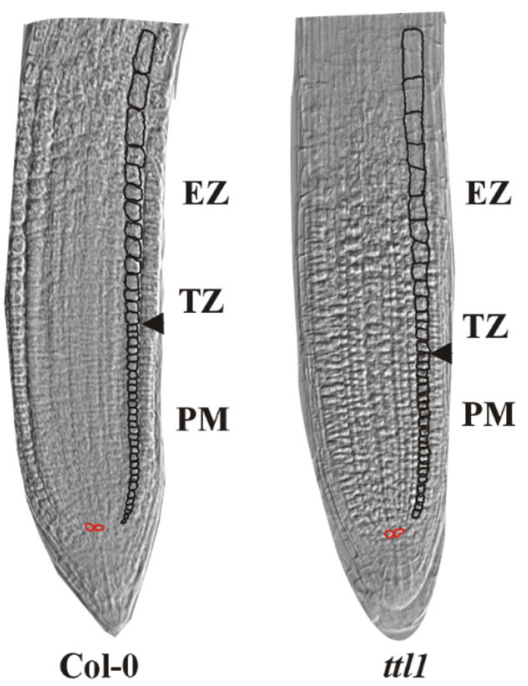

$\mathrm{C}$

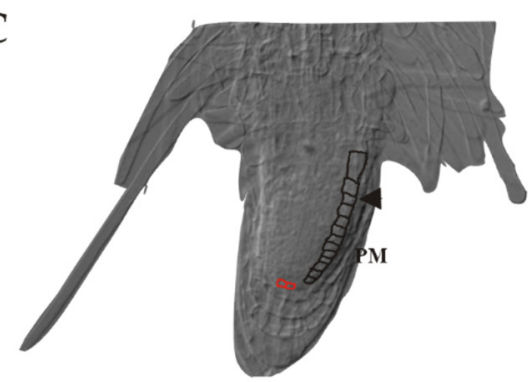

Col-0

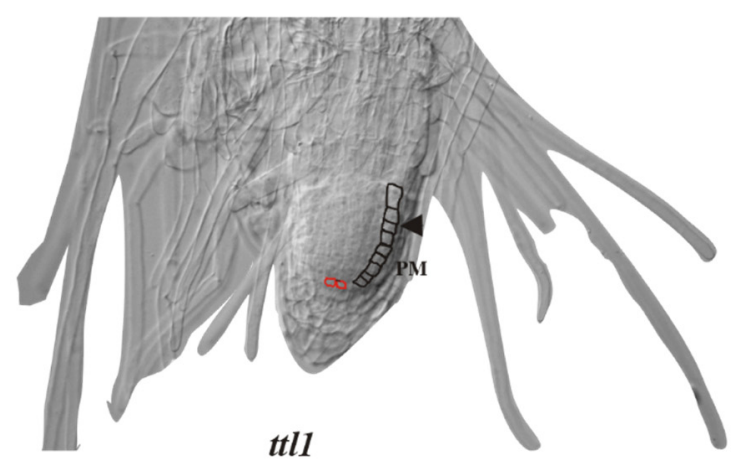

ttl1

Figure 1. The $t t l 1$ mutant exhibits greater reduction of root growth rate than Col-0 in response to increasing osmotic potential. (A) The graphic shows the root growth rate for Col-0 and $t t l 1$ grown during 10 and 7 days in control and stressing $-0.7 \mathrm{MPa}$ and $-1.2 \mathrm{Mpa}$ conditions, respectively. The magnitude of deceleration is higher in $t$ tl1. Different letters indicate statistically significant differences ( $\mathrm{t}$ Student $p<0.001 ; \mathrm{n}=30$ ). (B) Images of the root apical meristem of Col-0 and $t t l 1$ mutant grown in control conditions. (C) Images of the root apical meristem of Col-0 and ttl1 mutant after 7 days of growth in severe osmotic stress conditions (-1.2 MPa osmotic potential), showing the reduction in the number of cells in the proximal meristem (PM) and the reduction of the elongation zone (EZ) size. 
A
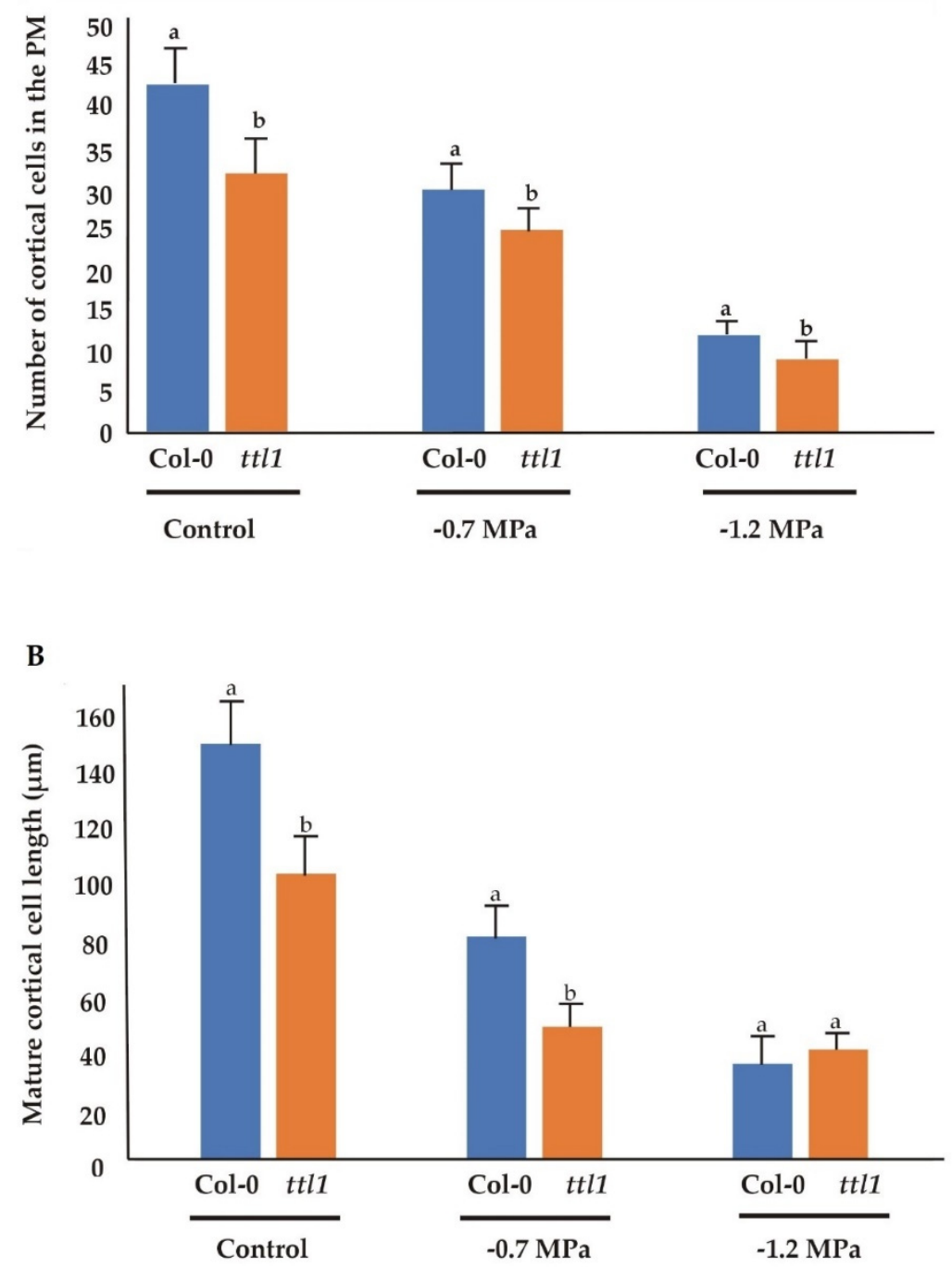

Figure 2. The number of cortical cells in the proximal meristem is reduced in $t t l 1$ mutant in correlation with the deceleration of root growth rate observed in osmotic stress condition. The figure shows the number of cortical cells in the proximal meristem (A) and the cortical mature cell length (B) for Col-0 and $t t l 1$ grown during 7 days in control, $-0.7 \mathrm{MPa}$ and $-1.2 \mathrm{MPa}$ osmotic stress conditions. Values are means \pm standard deviation (SD). Different letters indicate statistically significant differences ( $t$ Student $p<0.05 ; n=10$ ). The experiments were repeated three times.

Surprisingly, in control conditions, the $t t l 1$ mutant show a reduced number of cortical cells in the PM compared to Col- 0 and $t t l 1$ cells at maturity did not elongate to the same extent as Col- 0 cells (Figure 2). However, $t t l 1$ has a higher cell elongation rate in the PM than Col-0 (Figure 3C; Figure S5A) and the cells transit to the EZ faster than in Col-0 (Figure 3D). At $-0.7 \mathrm{MPa}$ of osmotic potential the cell number of the PM (Figures 1B and 2), as well as the mature cell length were reduced in $t t l 1$, explaining the root growth rate reduction in osmotic stress. The PM size reduction was due to a decrease in cell number in the PM and a premature transit towards the differentiation zone evidenced by epidermal cells closer to the QC acquiring differentiated characteristics (Figure 1C). The cell elongation rate estimated in the PM was reduced in the $t t l 1$ mutant indicating that the cells in the TZ did not reach a suitable size before transiting to the elongation zone under osmotic stress (Figure 3C). 

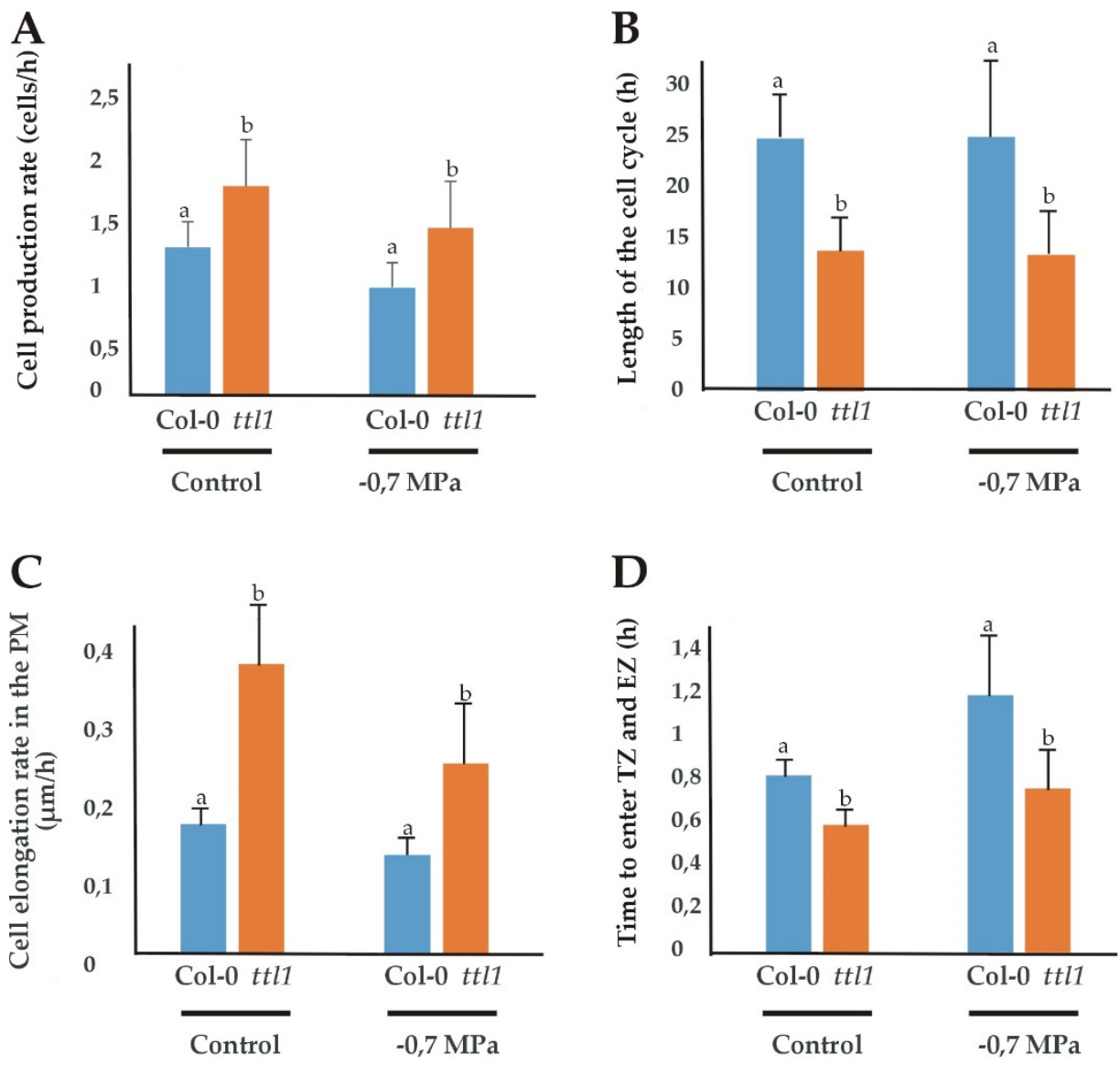

Figure 3. Growth parameters in the PM of Col- 0 and $t t l 1$ roots grown in control and osmotic stress conditions. The figure shows the cell production rate (cells $/ \mathrm{h})(\mathrm{A})$; the length of the cell cycle (h) (B); the cell elongation rate $(\mu \mathrm{m} / \mathrm{h})(\mathbf{C})$ and the time to enter the transition zone (TZ) and elongation zone (EZ) (D) for Col-0 and $t t l 1$ grown during 7 days in control and $-0.7 \mathrm{MPa}$ osmotic stress conditions. Values are means \pm standard deviation (SD). Different letters indicate statistically significant differences ( $t$ Student $p<0.05 ; n=10$ ).

\subsection{Osmotic Stress Increases Cell Wall Stiffness of Root Elongation Zone Cells}

Next, we studied the stiffness of epidermal cell walls in the root elongation zone of Col-0 and $t t l 1$ under control and osmotic stress using atomic force microscopy (Figure 4 and Table 1). The force curves on live cells of the root elongation zone showed lower indentation depth in Col-0 than in the $t t l 1$ mutant at an equally applied force (Figure S1A). A priori, these results indicate that Col-0 cell walls of epidermal cells in the elongation zone are stiffer. To confirm this, each curve was fitted by a second-order polynomial considering only the first $100 \mathrm{~nm}$ of each curve to avoid the effect of the substrate on the stiffness measurements. Figure S1B shows the Young's modulus normalized histogram obtained from Col-0 ( 3 seedlings, 201 force curves) and $t t l 1$ (3 seedlings, 1184 force curves) samples. Each histogram was fitted with a Gaussian curve to obtain the mean and standard deviation of the Young's modulus. The AEM of Col-0 $(88.12 \mathrm{KPa} \pm 2.79 \mathrm{KPa})$ was significantly different $(p<0.05)$ from that of ttl1 mutant $(16.08 \mathrm{KPa} \pm 6.87 \mathrm{KPa})$. The mean of the elastic modulus was $448 \%$ higher for Col-0 than $t t l 1$ mutant (Table 1 and Table S4). 

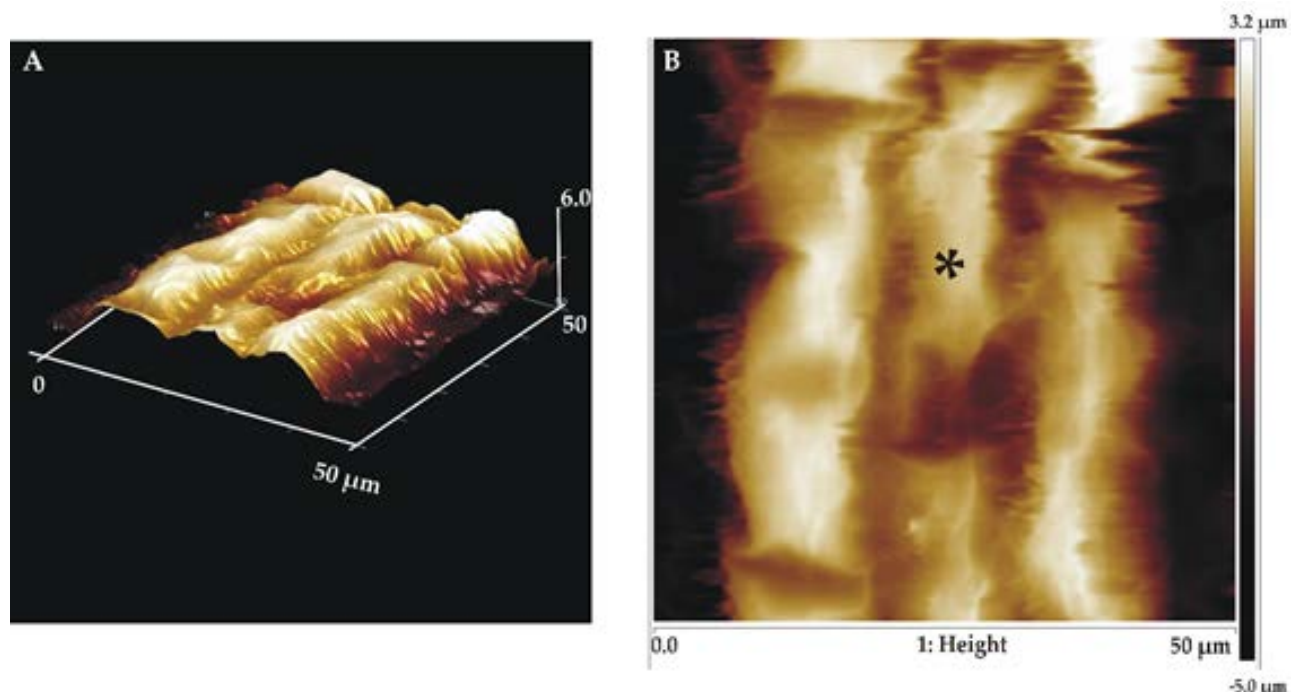

Figure 4. Atomic force microscopy (AFM) imaging of the surface of the root elongation zone cells at high resolution. Topography of a small area $(50 \times 50 \mu \mathrm{m})$ of the root elongation zone using contact mode in fluid. Friction image of a few cells of the root elongation zone of Col-0 (A); height images of the same zone of Col-0 indicating the location where force curves were obtained $(\mathbf{B})$. * indicates the location where force curves were obtained.

Table 1. Cell walls apparent elastic modulus measured in cells of the elongation zone of roots of Col-0, ttl1, prc1-1 and ttl1prc1-1 grown in control conditions.

\begin{tabular}{cccc}
\hline Control & $\mathbf{Y}(\mathbf{k P a})$ & $\mathbf{N}$ & Error \\
\hline Col-0 & $88.12 \pm 2.79 \mathrm{a}$ & 201 & 0.19 \\
$t t l 1$ & $16.08 \pm 6.87 \mathrm{~b}$ & 1184 & 0.19 \\
$\operatorname{prc1-1}$ & $18.08 \pm 8.04 \mathrm{c}$ & 2231 & 0.17 \\
$t t l 1$ prc1-1 & $27.06 \pm 8.5 \mathrm{~d}$ & 1052 & 0.26 \\
\hline
\end{tabular}

Values are means \pm SD; 200-2231 force curves were obtained from the central part of elongation cells of 3 roots for each growing condition. Seedlings were attached to petri dishes with silicone and covered with $1 \times$ phosphate-buffered saline (PBS) solution. Normalized Young's modulus histograms were obtained from all experimental conditions. Each histogram was fitted with a Gaussian curve. Statistical significance is as follows: $p<0.05$ (by Student's $t$-test) for a vs. $\mathrm{b}$ and $p<9.8971 \times 10^{-306}$ (by Student's $t$-test) for c vs. d.

Under osmotic stress, the force curves on live cells also showed that the cell wall of Col-0 is stiffer than the cell wall of the $t t l 1$ mutant (Figure S2A). Figure S2B shows the Young's modulus normalized histogram obtained from all Col-0 (3 seedlings, 263 force curves) and $t$ tl1 mutant ( 3 seedlings, 324 force curves) samples grown in osmotic stress. The AEM of Col-0 $(164.98 \mathrm{KPa} \pm 2.66 \mathrm{KPa})$ was significantly different $\left(p<9.8971 \times 10^{-306}\right)$ from that of $t t l 1$ mutant $(29.71 \mathrm{KPa} \pm 13.9 \mathrm{KPa})$. The mean of the elastic modulus was $455 \%$ higher for Col-0 than the $t t l 1$ mutant (Table 1 and Table S4). Interestingly, after 7 days of osmotic stress, we observed that the cell wall of epidermal cells of the elongation zone of both Col-0 and $t t l 1$ get $87 \%$ and $84 \%$ stiffer, respectively (Table 2 and Table S4).

To investigate whether the $t t l 1$ stiffness-defective phenotype could be related to defects in cell wall structural composition, we analyze the mechanical properties of the cell walls of EZ cells of prc1-1, a CESA6-null mutant that present a 50\% reduction in the content of crystalline cellulose [35]. Even though the AEM of $t+l 1$ was statistically different from the AEM of prc1-1, it was in the same order of magnitude in control conditions (Table 1 and Table S4). For both mutants cell walls of epidermal cells in the elongation zone stiffen in response to osmotic stress (Table 2 and Table S4). However, neither reaches the order of magnitude of Col-0, explaining the swelling phenotype observed in this condition (Tables 1 and 2; Table S4). As prc1-1 is known to have less cellulose crystalline in its cell 
walls [35] our data suggests that $t t l 1$ may have a different composition or organization of its cell wall compared to Col-0.

Table 2. Cell walls apparent elastic modulus measured in cells of the elongation zone of roots of Col-0, ttl1, prc1-1 and ttl1prc1-1 grown in osmotic stress conditions (-1.2 MPa).

\begin{tabular}{cccc}
\hline Osmotic Stress (-1.2 MPa) & $\mathbf{Y ~ ( k P a )}$ & $\mathbf{N}$ & Error \\
\hline Col-0 & $164.98 \pm 2.66 \mathrm{a}$ & 263 & 0.16 \\
$t t l 1$ & $29.71 \pm 13.9 \mathrm{~b}$ & 324 & 0.77 \\
$\operatorname{prc1-1}$ & $51.54 \pm 24.86 \mathrm{c}$ & 1161 & 0.72 \\
\hline
\end{tabular}

Values are means \pm SD; 200-1161 force curves were obtained from the central part of elongation cells of 3 roots for each growing condition. Seedlings were attached to petri dishes with silicone and covered with $1 \times$ PBS phosphate-buffered saline (PBS) solution. Normalized Young's modulus histograms were obtained from all experimental conditions. Each histogram was fitted with a Gaussian curve. Statistical significance is as follows: $p<0.05$ (by Student's $t$-test).

We calculated the level of epistasis by comparing the AEM ttl1prc1-1 value of the double mutant with the product of the AEM $t+11$ and AEM prc1-1 values of the corresponding single mutants. The epistasis mean value for the ttl1prc1-1 double mutant grown in control conditions was $0.2 \pm 0.1$. Epistatic interactions help to elucidate functional association between genes; in this case, the values obtained suggest that TTL1 and CESA6 could participate in a sequential manner in the process of cell wall formation [42].

The ttl1prc1-1 double mutant had a slower root growth rate than Col- 0 and $t t l 1$ in control conditions (t Student $p<0.001 ; n=30$; Figure S3). In this condition the number of cells in the PM of the double mutant $(27 \pm 2)$ was significantly different (Student's $t$-test $p<0.05)$ from Col-0 (43 \pm 5$)$ and $t t l 1(33 \pm 5)$ but did not differentiate from prc1-1 $(27 \pm 2)$. The length that cells reached at maturity was significantly shorter in the double mutant in comparison to $t t l 1$, prc1-1 and Col-0 (Table S5). Due to the extreme phenotype of $t t l 1 p r c 1-1$ grown for 7 days in $-1.2 \mathrm{MPa}$ we were unable to obtain force curves that allowed us the proper analysis (Figure 44 ).

The root growth rate in control conditions of the ttl1prc1-1 is significantly lower than Col-0, $t t l 1$ and $p r c 1-1$ (Figure S3). Additionally, the root growth rate decelerated more in the ttl1prc1-1 double mutants than in the single mutants at increasing osmotic potential. Interestingly, at $-0.7 \mathrm{MPa}$, both the cell number at the PM and the mature cell length were significantly reduced in ttl1prc1-1 compared to Col-0, ttl1 and prc1-1 (Table S6). At $-1.2 \mathrm{MPa}$ there was a significant reduction in the number of cells in the PM of ttl1prc1-1, but there were no differences in the mature cell length with Col-0 $t$ tl1 and prc1-1 (Table S7).

\subsection{Cell-Specific Root Expression Analysis of TTL1 Using Transgenic pTTL1::GUS Plants}

In order to get further insight into the role of TTL1, we used the pTTL1::GUS transcriptional line previously reported [32]. We first analyzed the expression pattern of TTL1 during primary root development. Specific GUS staining was observed at the QC since the second day post-germination until day 4 . At day 5 post-germination, GUS staining spread towards cells of the cortex, endodermis, and stele in the PM and TZ (Figure 5). These observations are consistent with the expression pattern reported in the publicly available microarray data present in the Electronic Fluorescent Pictograph browser [44] for roots spatiotemporal data [45] in which the highest levels of TTL1 expression were found in the QC (134.83 \pm 30.83$)$ and the epidermis and columella lateral (183.33 \pm 11.93$)$, followed by columella cells $(82.61 \pm 23.1)$, cortex (75.72 \pm 7.76$)$ and stele $(68.45 \pm 21.83)$. The expression values are mean and standard deviation of ATH1 normalized data by GCOS method, TGT value of 100. Values are average of two to three replicates, with spatiotemporal expression levels imputed by an EM algorithm [46] 


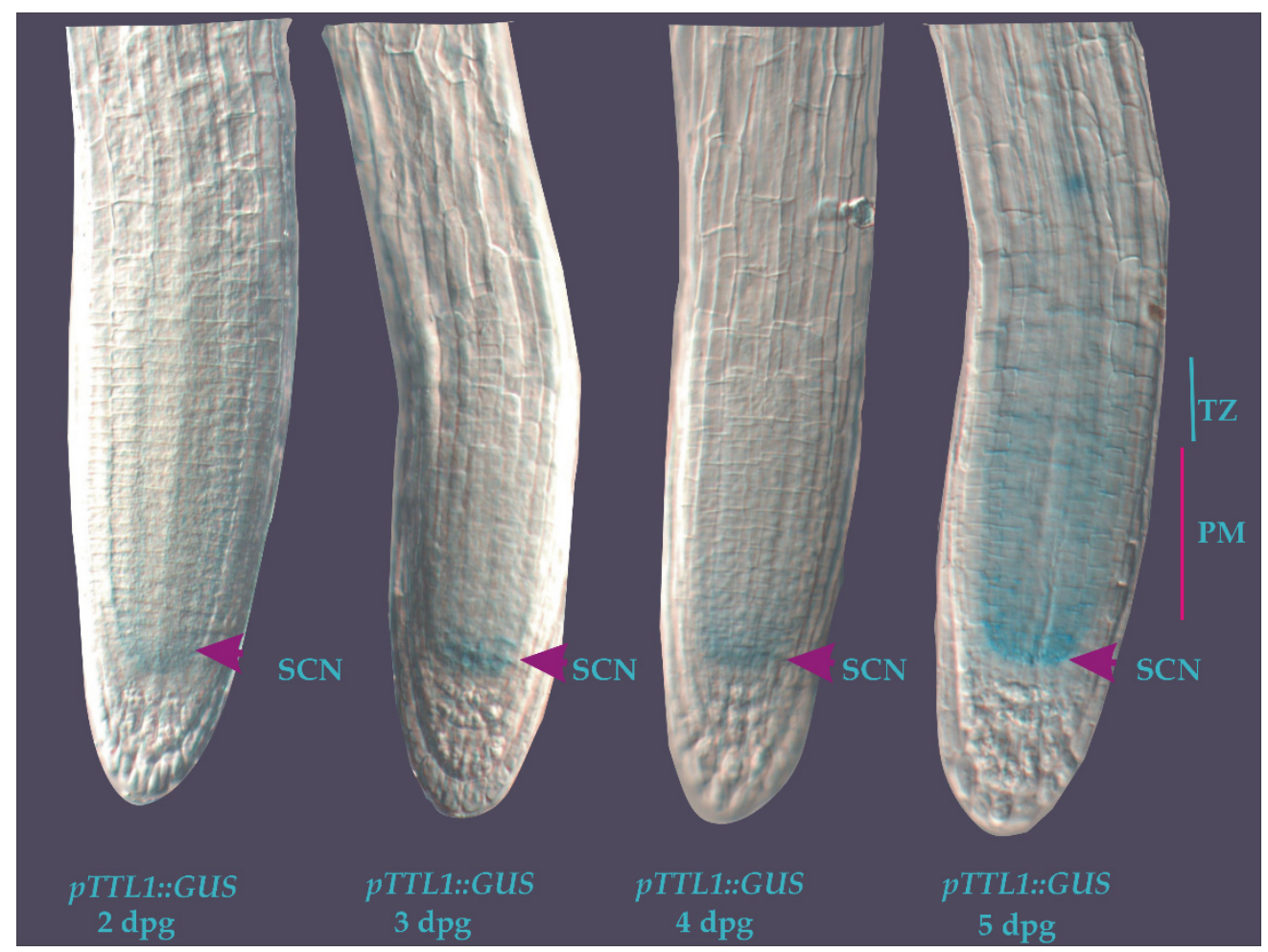

Figure 5. Expression patterns of TTL1 in Arabidopsis primary root using promoter::GUS analysis from 2 to 5 days post germination in control medium. pTTL1::GUS roots showing GUS signal in the stem cell niche (SCN) from 2 to $4 \mathrm{dpg}$ (arrowheads). At $5 \mathrm{dpg}$ the signal is also localized in the cortex, endodermis, and stela cells in the PM and transition zone (TZ). $n=15$.

3.4. TTL1 Expression Analysis in the Primary Root in Response to Hyperosmotic Stress and Hormonal Regulation

Next, we investigated the expression of TTL1 in response to indole acetic acid (IAA), epibrassinolide (BL) and the BR biosynthesis inhibitor propiconazole (PCZ) in the roots of $7 \mathrm{dpg}$ pTTL1::GUS seedlings growing in control and under osmotic stress. The GUS signal in $7 \mathrm{dpg}$ seedlings grown in control media was localized to the SCN, PM, TZ and EZ. In the PM the signal was more intense in epidermis, cortex and endodermis in comparison to the stele. At the TZ and EZ a paler signal was observed (Figure 6). Roots of pTTL1::GUS seedlings exposed for $30 \mathrm{~min}$ in control media supplemented with $0.1 \mu \mathrm{M}$ IAA increased the GUS signal in epidermal cells compared to roots in medium without IAA (Figure 6). pTTL1::GUS roots exposed for $30 \mathrm{~min}$ to $0.2 \mu \mathrm{M}$ BL showed the GUS signal in the lateral root cap and epidermal cells (Figure 6). Finally, in pTTL1::GUS roots grown in presence of $0.5 \mu \mathrm{M}$ PCZ GUS signal was localized in the columella, lateral root cap and epidermis (Figure 6). Interestingly, both IAA and PCZ treatments increased the GUS signal in the epidermis at a similar level. Thirty minutes of osmotic stress caused a severe and transient reduction of the GUS signal in the roots of pTTL1::GUS seedlings (Figure 6) that re-appear after $1 \mathrm{~h}$ of stress treatment (Figure S6).

The only treatment able to restore GUS signal to the localization and intensity of the control condition under osmotic stress was the treatment with $0.5 \mu \mathrm{M} \mathrm{PCZ}$ (Figure 6).

\subsection{DR5::GUS Signal Localization in the Quiescent Center (QC) Did Not Change during the Exposure to Severe Osmotic Stress}

Next, we determined whether the changes in $t t l 1$ root growth observed during osmotic stress were related to the known mechanisms regulating root growth. First we investigated the auxin gradients in $t t l 1$ using the well-stablished DR5::GUS marker [47]. 


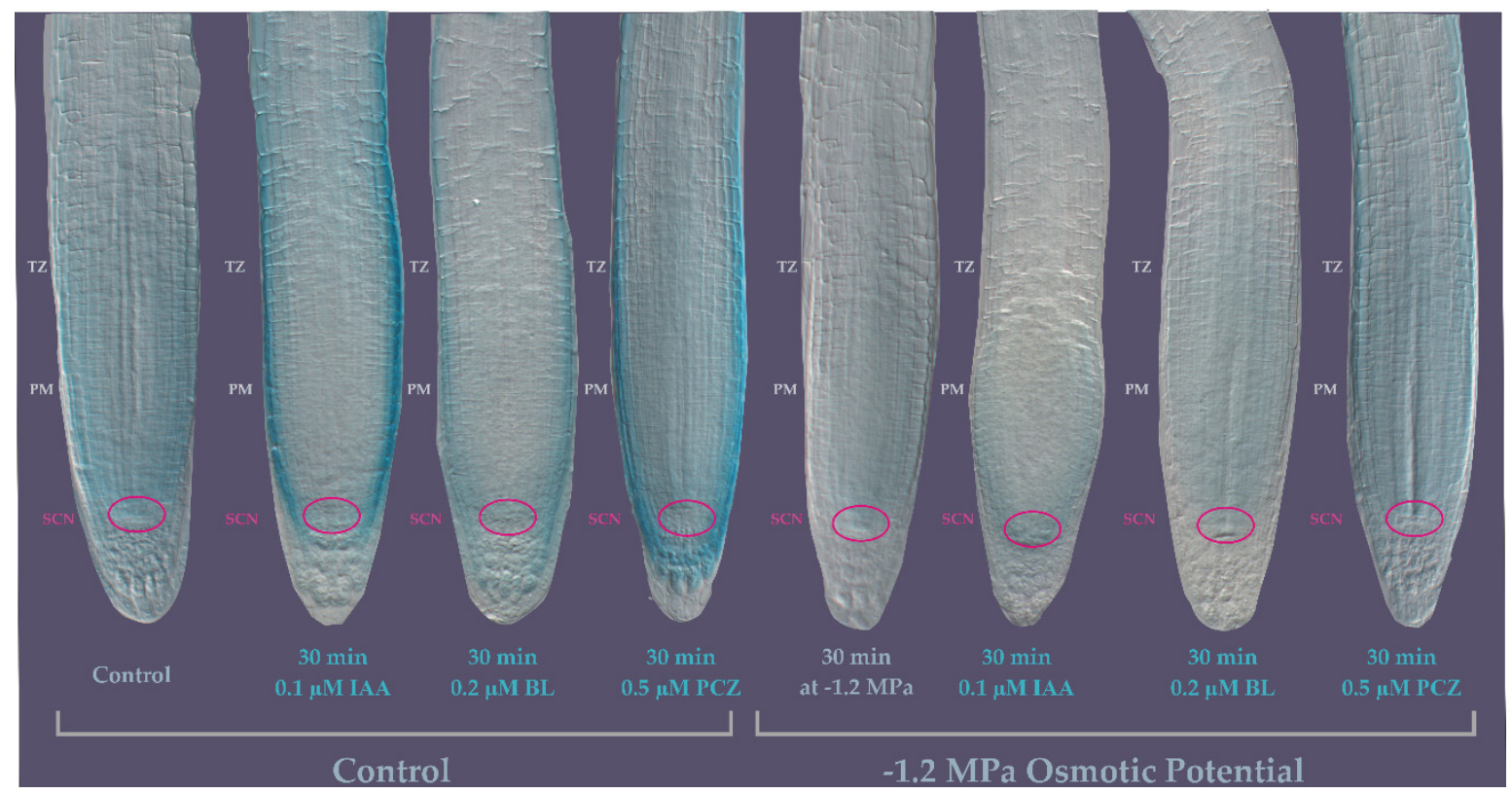

Figure 6. Expression patterns of TTL1 Arabidopsis primary root using promoter::GUS analysis in response to osmotic potential and hormones. pTTL1::GUS roots grown in control conditions showing GUS signal localized to the stem cell niche (SCN) and the proximal meristem (PM) epidermis, cortex, endodermis and stele. pTTL1::GUS roots exposed during 30 min to control medium supplemented with $0.1 \mu \mathrm{M}$ IAA showing GUS signal localized in the epidermis. pTTL1::GUS roots exposed during $30 \mathrm{~min}$ to control medium supplemented with $0.2 \mu \mathrm{M}$ BL showing GUS signal in lateral root cap and epidermal cells. pTTL1::GUS roots exposed during 30 min to control medium supplemented with $0.5 \mu$ M PCZ showing GUS signal in columella, lateral root cap and epidermal cells. pTTL1::GUS roots grown in -1.2 MPa osmotic potential medium showing almost no GUS signal in the SCN and PM. pTTL1::GUS roots exposed during $30^{\prime}$ to -1.2 MPa osmotic potential medium supplemented with $0.1 \mu \mathrm{M}$ IAA showing a pale signal in epidermal and cortex cells in the PM. pTTL1::GUS roots exposed during $30 \mathrm{~min}$ to $-1.2 \mathrm{MPa}$ osmotic potential medium supplemented with $0.2 \mu \mathrm{M}$ BL showing a pale GUS signal in the PM. pTTL1::GUS roots exposed during $30 \mathrm{~min}$ to $-1.2 \mathrm{MPa}$ osmotic potential medium supplemented with $0.5 \mu \mathrm{M}$ PCZ showing a pale GUS signal distributed similar to the one observed in control conditions without hormones supplemented. $n=15$.

For this, we introduced the DR5::GUS marker into the $t t l 1$ by crossing. As shown in Figure 7A,B, DR5::GUS had a similar expression pattern in Col- 0 and $t t l 1$ background. However, monitoring the roots of DR5::GUS seedlings during 7 days of severe osmotic stress showed that there was a significant decrease of the signal in the $t t l 1$ mutant (Figure 7B) compared to Col-0 (Figure 7A) suggesting that TTL1 could mediate part of the components of root growth through auxin response during osmotic stress.

\subsection{Osmotic Stress Suppresses Brassinosteroids (BR) Signaling in Epidermal Cells of Elongation Zone (EZ)}

It has been reported that BZR1 has a specific pattern of expression in the epidermal cells of the root apical meristem and that the level of nuclear BZR1 provides a readout of BR signaling [17]. BZR1-YFP fusion protein driven by a constitutive 35S promoter accumulated at a low level in the nuclei of cells in SCN and at a high level in the nuclei of epidermal cells in TZ and EZ in correlation with rapid cell elongation [17]. In order to analyze if the BR signaling is affected in the $t t l 1$ mutant during osmotic stress we crossed $t t l 1$ with $35 S:: B Z R 1:: Y F P$ and selected a $t t l 1$ carrying the 35S::BZR1::YFP marker. The expression of $35 S:: B Z R 1:: Y F P$ in the roots of $t t l 1$ seedlings grown in control conditions showed a similar pattern to that of Col-0, i.e., nuclear localization increased as cells enters the TZ-EZ (Figure 8A). We observed that the cells of the $\mathrm{TZ}$ of the $t t l 1$ mutant showed a change in the characteristic shape of the nuclear signal (zoom in Figure 8B), where the nucleus seemed to be compressed to the sides of the cells which suggests that the cellular expansion begins earlier in the $t t l 1$ mutant. In response to $5 \mathrm{~h}$ of severe osmotic stress $(-1.2 \mathrm{MPa}$ of 
osmotic potential) BZR1 pattern localized mostly in the cytoplasm in the EZ epidermal cells in both Col-0 and ttl1 mutant (Figure 8D-F). However, this pattern begins in cells closer to the PM in the $t t l 1$ mutant than in Col-0 (Figure 8D-F). This pattern of BZR1 in response to osmotic stress agreed with the observation that Col-0 mature cells experienced a $46 \%$ of length reduction during severe osmotic stress compared to the control condition and the $t t l 1$ mutant mature cells a $73 \%$ of length reduction during severe osmotic stress compared to Col-0 in control conditions (Figure 2). These observations suggested that the reduction in elongation in EZ cells during osmotic stress can partially be explained by the BR signaling pathway.

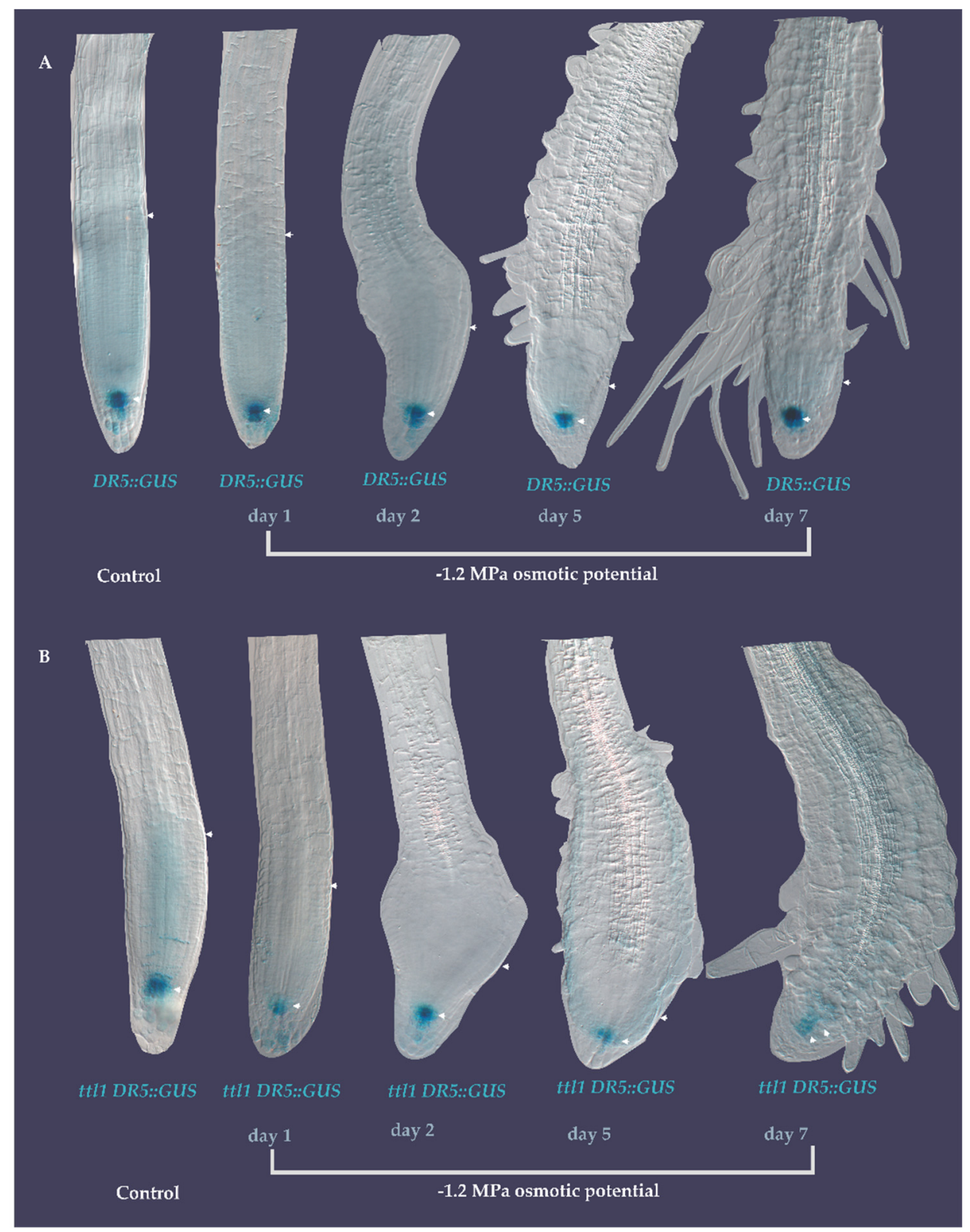

Figure 7. Expression pattern of auxin in response to 7 days of severe osmotic stress. (A) DR5::GUS in Col-0 in control medium and during 7 days of severe osmotic stress showing localization in the QC. (B) DR5::GUS in $t t l 1$ mutant showing the same localization as in Col-0. Arrowheads indicate the size of the PM (from the QC to the TZ). 


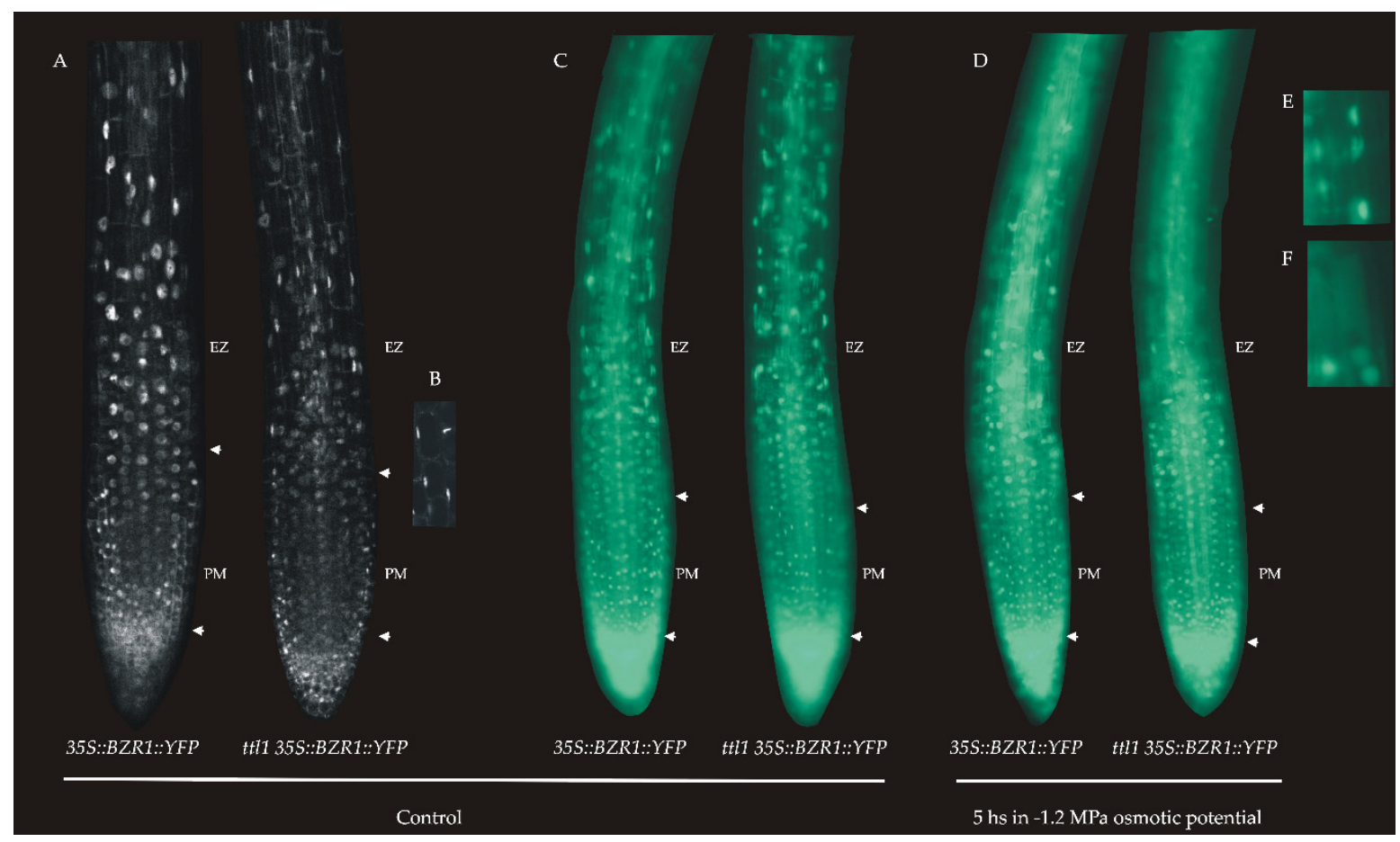

Figure 8. (A) Expression pattern of BZR1 in roots of Col-0 and $t+l 1$ mutant grown during 7 days in control conditions. (B) Zoomed in view of TZ showing the nuclear expression pattern in $t t l 1$. This pattern suggests that cellular expansion begins earlier than in Col-0. Images were taken with Confocal Microscopy Zeiss LSM800-AiryScan $n=10$. (C-F). Expression pattern of brassinosteroids (BR) in response to $5 \mathrm{~h}$ of severe osmotic stress. (C) 35S::BZR1::YFP in Col-0 and ttl1 mutant plants grown in control medium showing the YFP signal in the nuclei of EZ epidermal cells. (D) $35 S:: B Z R 1:: Y F P$ in Col-0 and $t t l 1$ mutant plants grown during $5 \mathrm{~h}$ of severe osmotic stress showing YFP signal localized in the cytoplasm of epidermal EZ cells. (E) Zoomed in view of signal in epidermal EZ cells of $t t l 1$ mutant grown in control condition showing the nuclei localization of YFP signal. (F) Zoomed in view of signal in epidermal EZ cells of $t t l 1$ mutant grown in hyperosmotic condition showing the cytoplasmic localization of YFP signal. Images were taken with Epifluorescence microscope ZEIZZ-AXIO Imager. M2.

\subsection{Exogenous BR Application Did Not Recover the Root Length Reduction of ttl1 Grown under Osmotic Stress}

$\mathrm{BR}$ at $\mathrm{nM}$ to $\mu \mathrm{M}$ concentrations have inhibitory effects on primary root growth [48]. Moreover, the use of PCZ also produce a reduction in primary root growth [49]. The finding that the homologous TTL3 protein interacts in vivo with most BR signaling components [33] makes us evaluate a possible role of TTL1 in BR signaling. It was previously described that $t t l 1$, similarly to $t t l 3$ and $t t l 4$, presented a decreased sensitivity to BL when seedling grown for 4 days in half strength MS medium were transferred to the same medium supplemented with $0.1 \mu \mathrm{M}$ of $\mathrm{BL}$, and root length was measured 6 days later [33]. To further investigate the effect of BR inhibiting concentrations on primary root length, we tested $t t l 1$ root elongation in our phenotypic analysis experimental conditions. After 5 days of growth in control medium, plus 9 days of growth in control medium supplemented with $0.2 \mu \mathrm{M}$ of BL, Col-0 root length was $72 \%$ compared to control conditions (Table 3 and Table S8). However, the $t t l 1$ mutant showed more sensitivity to $\mathrm{BL}$, since the root length of $t t l 1$ grown in control medium supplemented with $0.1 \mu \mathrm{M}$ of BL was $66 \%$ compared to the root length of Col-0 grown in control conditions and $58 \%$ when grown in control medium supplemented with $0.2 \mu \mathrm{M}$ of BL (Table 3 and Table S8). This result supports the possibility that $t t l 1$ is defective in BR signaling and also suggests that the inhibition of root growth by BL in $t t l 1$ may be less or greater than Col-0 depending on the age of the seedlings and/or the duration of the BR treatment. The upregulation of BR biosynthetic genes has been reported for BR signaling mutants such as bri1-5 [50], bri-301 [51], and bik1 [52] and is caused by a lack of feedback regulation in the expression of these biosynthetic genes [53-55]. It is possible 
that BR biosynthetic genes are induced in $t t l 1$ after large periods (9 days) of BL treatment, overcompensating its initial hyposensitivity to BR.

Table 3. Root length of Col- 0 and ttl1 after 9 days of growth in medium with, $0.2 \mu \mathrm{M}$ of BL, $0.5 \mu \mathrm{M}$ of PCZ, without or with supplementation of $400 \mathrm{mM}$ of Mannitol.

\begin{tabular}{|c|c|c|c|c|c|c|c|c|}
\hline \multicolumn{9}{|c|}{$\begin{array}{c}\text { Comparison to Col-0 Grown in Control Conditions } \\
\text { Root Length Reduction Effect }\end{array}$} \\
\hline & & \multicolumn{3}{|c|}{ Control } & \multicolumn{4}{|c|}{$400 \mathrm{mM}$ Mannitol } \\
\hline & & $0.5 \mu \mathrm{M}$ PCZ & $0.1 \mu \mathrm{MBL}$ & $0.2 \mu \mathrm{M} \mathrm{BL}$ & $0.2 \mu \mathrm{M} \mathrm{BL}$ & $0.1 \mu \mathrm{M} B \mathrm{BL}$ & $0.5 \mu \mathrm{M}$ PCZ & \\
\hline Col-0 & 100 & 80 & 81 & $72 *$ & $78^{*}$ & $65^{*}$ & $61 *$ & $55^{*}$ \\
\hline$t t l 1$ & 98 & $67 *$ & $66^{*}$ & $58 *$ & $57^{*}$ & $45^{*}$ & $41^{*}$ & $47^{*}$ \\
\hline
\end{tabular}

In addition, we studied the effect of PCZ in the root length. After 9 days of growth in control medium supplemented with PCZ we did not observe significant differences in Col-0 root length compared with Col-0 roots grown in control medium (Table 3 and Table S8), but the root length of $t t l 1$ was $67 \%$ compared to Col- 0 root length grown in control conditions (Table 3 and Table S8). The response of $t t l 1$ was similar to the observed in bri1-5 suggesting that $t t l 1$ responds to changes in BR homeostasis [49].

Furthermore, we evaluated the root length in hyperosmotic media and hyperosmotic media supplemented with BL or PCZ (Table 3 and Table S8). Interestingly, growth during 10 days in control medium supplemented with BL produced a reduction in the length of the root of $t t l 1$ mutant as severe as 9 days growing in severe osmotic stress (Table 3 and Table S8). The combination of $400 \mathrm{mM}$ Mannitol $+0.2 \mu \mathrm{M}$ of BL produced Col- 0 roots $20 \%$ longer than in $400 \mathrm{mM}$ de Mannitol. On the contrary, BL did not produce significant changes in the length of $t t l 1$ roots growing in osmotic stress (Table 3 and Table S8). We did not find a significant effect on root length of both genotypes of PCZ in osmotic stress conditions (Table 3 and Table S8).

In summary, the effect of recuperation of the root length of BL treatment observed in Col-0 roots growing in hyperosmotic medium that was not observed in the $t+l 1$ mutant suggests a possible connection between TTL1, BR and root growth osmotic stress adaptation.

\section{Discussion}

Water availability is a factor that strongly limits plant growth and its uptake by the roots is affected by many abiotic stresses such as drought [12,21,56-58]. Roots sense drought through specific cell types such as stem, cortical and vascular cells and respond adaptively to avoid dehydration, [4,59-63]. Auxins modulates root elongation in the RAM [64], abscisic acid (ABA) participate in EZ cortex cells sensing water potential [65] and vascular BRL3 overexpression confers drought resistance [63].

TTL proteins comprise a novel family of proteins that are specific to plants that appeared in the transition from aquatic environments to land, hinting at their potential role in plant drought-stress adaptation during terrestrial colonization $[31,32,66]$. Mutations in the Arabidopsis TTL1 gene cause reduced tolerance to osmotic stress evidenced by an arrest in root growth and root swelling, which makes it an interesting model for exploring how root growth is regulated under osmotic stress conditions [31-33]. In this work we evaluated primary root growth of the $t t l 1$ mutant during 7 days of growth comparing two osmotic potentials $(-0.7 \mathrm{MPa}$ and $-1.2 \mathrm{MPa})$ generated with mannitol. Interestingly, $t t l 1$ root growth rate decelerates with increasing osmotic potential and this reduction is significantly greater than the Col-0 root growth rate reduction. During osmotic stress, the reduction in primary root growth rate could be explained by the inhibition in cell elongation in EZ (measured by the reduction in mature cell length) followed by the reduction in the 
number of cortical cells in the PM. Similar results were obtained in response to saline and osmotic stress in Arabidopsis [15,20,23]. At -0.7 MPa osmotic potential mature cell length was more affected than the cell number at the PM, whereas at $-1.2 \mathrm{M}$ Pa both parameters were strongly affected. This points out that the severity of the stress affects each domain of the RAM differently, as described before for the meristematic zone and the transition zone of the root [23]. In this study, at $-0.7 \mathrm{MPa}$ of osmotic potential we observed a premature cell transit towards the transition and elongation zone and to the differentiation zone coincident with the observation of epidermal cells closer to the QC acquiring differentiated characteristics as previously described for Col-0 accession growing in hyperosmotic conditions [23].

Cellular expansion plays an important role during root growth and development. In cells that expand longitudinally, cellulose microfibrils are deposited perpendicular to the expansion axis, restricting radial expansion $[25,43]$. The fact that cellulose deficient mutants have swelling phenotypes and slower root growth rates, indicate that at the cellular level, the size, the expansion direction [10] and the mechanical properties of the cell wall itself contribute to the signaling process of root growth arrest [22,57]. In this work, we observed that mature cell length was reduced with the severity of the osmotic stress, at $-0.7 \mathrm{MPa}$ mature cell length was significantly different between Col- 0 and $t t l 1$; at $-1.2 \mathrm{MPa}$, however, mature cell length was not statistically different between genotypes. These data suggest the existence of a minimal cell length threshold, and/ or that the physical properties of the cell wall contribute to the signaling process to sustain root growth rate in osmotic stress.

We observed that the $t t l 1$ root swelling phenotype was enhanced at severe osmotic stress condition $(-1.2 \mathrm{MPa})$ and appeared after the second day of growth in osmotic stress affecting epidermis and cortex cells in the TZ. Interestingly, it was also present in Col-0, however in this case as the time of exposure to stress progresses the cells in the TZ of Col- 0 adapted and the swelling phenotype disappeared. Some authors reported that Col-0 epidermal and cortex cells swell when the roots were subjected to a hyperosmotic shock $(-1.2 \mathrm{MPa})$ [23], or to saline stress [67], and this has also been reported in plants with altered cell wall biogenesis $[24,34,35,68,69]$. The swelling phenotype is determined by the physicochemical properties of the cell wall $[21,22,27]$. The TZ domain is characterized by the cell wall structure alterations and vacuolization preparing the cells for the rapid elongation in the EZ which makes the TZ more sensitive to the osmotic perception and suitable to develop the swelling phenotype [20].

To examine whether osmotic stress and TTL1 affect the cell wall's mechanical properties at the EZ, we used atomic force microscopy (AFM). Unexpectedly, in control conditions, the elastic modulus' mean was $448 \%$ higher for Col- 0 than $t t l 1$ mutant, meaning that $t t l 1$ has its cell walls more elastic. Moreover, after 7 days of severe osmotic stress $(-1.2 \mathrm{MPa})$, we found that the cell wall's stiffness in the EZ increases. Even though, both genotypes behave in this way, the increase in stiffness observed in the cell walls of the EZ cells of the $t t l 1$ mutant did not reach the magnitude of the stiffness of Col-0 cell walls, explaining why the root swelling phenotype persists in the mutant.

Analysis of the mechanical properties of the cell walls of EZ cells of prc1-1 mutant indicated that the cell walls of epidermal cells in the EZ of prc1-1 were more elastic than Col0 , as was already reported for all the cesa mutants in the shoot apical meristem (SAM) [70]. This agreed with the reduced content of crystalline cellulose of prc1-1 [35]. Moreover, the root growth rate and AEM of the ttl1prc1-1 double mutant showed that TTL1 genetically interacts with CESA6.

Feng et al., 2018 reported that after salt treatment, the cell walls of the epidermal cells in root EZ of wild-type Arabidopsis has an overall drop in wall stiffness, which they recovered at the beginning of the growth recovery phase. However, mutants with impaired cell wall integrity as fer failed to restore cell wall stiffness. In our conditions we did not see a drop in wall stiffness after osmotic stress, showing that osmotic stress induced by $\mathrm{NaCl}$ include also an ionic stress, supporting the hypothesis that sodium ions could directly disrupt load-bearing ionic interactions with the wall [22]. 
Auxin and BR have been proved to act antagonistically in the process of cell elongation in the root. Transcriptomic analysis in wild type plants showed that BR-induced but auxin-repressed genes tend to be related to cell-wall organization and biogenesis and water transport, whereas BR-repressed but auxin-induced genes tend to be involved in ribosome biogenesis [17]. At the cellular level, auxin treatment to the wild-type plants reduced cell elongation and increased lateral cell expansion in the meristem zone and radial dimension of root tip, in contrast to BR. Furthermore, auxin treatment to the wild-type plants dramatically inhibited cell elongation in the elongation zone [17]. The wild-type roots treated with BL showed early initiation of elongation in the transition zone, whereas IAA showed similar initiation of the elongation as the mock but failed to elongate further in the elongation zone compared to BL-treated roots and the mock condition [17]. Furthermore, reaching a critical cell size is affected by BR controlling the expansion process through cell wall modification, leading to a normal progression of the cell cycle, and contributing to the establishment of the size of the root meristem. BRI1 activity in the epidermis initiates a signal that regulates gene expression of the inner meristematic cell files [14].

When we investigated the role of TTL1 focusing on auxin and BR signaling the auxin response pattern did not change in the $t t l 1$ mutant during hyperosmotic stress, thus the DR5::GUS signal localized to the QC as in Col-0, although its intensity diminished as the treatment with osmotic stress advanced. In addition, $5 \mathrm{~h}$ of hyperosmotic stress was enough to delocalize BZR1 from the nucleus of epidermal cells of the root EZ, in both genotypes, suggesting that osmotic stress also dynamically represses the BR signaling pathway as was mentioned for saline stress [15]. These observations concur with the fact that mature cell length was more affected by osmotic stress in $t t l 1$ than the number of cells in the PM.

Interestingly, $t+l 1$ has a reduced number of cortical cells in the PM compared to Col-0 that did not elongate to the same extent as Col-0 cells. A reduced PM size and mature cell length is also observed in the BR-deficient mutant $d w f 4$ and the BR insensitive mutant bri1 $[13,14,17,39]$. The BZR1 pattern confirmed that the elongation rate of PM cortical cells is faster in $t t l 1$ mutant in control conditions, resembling what is observed when Col-0 roots are treated with BL [17]. However, $t t l 1$ mature cell size in control conditions, shorter than in Col-0, resembled more the effect of the combination of auxin and BR treatment to Col-0 [17]. Our study revealed that $p$ TTL1::GUS respond to auxins, BR, PCZ increasing the intensity of the signal in the epidermis of both meristematic zones. It was previously described that $t t l 1$ presented a decreased sensitivity to BL [33]. In this study, $t t l 1$ showed more sensitivity to BL than Col-0, supporting the notion that $t t l 1$ is defective in BR signaling and suggests that the inhibition of root growth by BL in $t t l 1$ may be less or greater than Col-0 depending on the age of the seedlings and/or the duration of the BR treatment. The upregulation of BR biosynthetic genes has been reported for BR signaling mutants such as bri1-5 [50], bri1-301 [51], and bik1 [52] and is caused by a lack of feedback regulation in the expression of these biosynthetic genes [53-55]. It is possible that the BR biosynthetic gene is induced in $t t l 1$ after large periods of BL treatment, overcompensating its initial hyposensitivity observed to BR. Whether all the observed changes are direct effects of BR homeostasis or emerge indirectly, for example, from hormonal crosstalk with auxin, remains to be determined.

pTTL1::GUS signal was visible in the QC from day 2 to day 5 after germination and the $t t l 1$ mutant has less cortical cells at the PM at day 7 after germination, further informing the possible function of this gene during PM size determination. In control conditions, 7 days after germination the $p T T L 1::$ GUS signal appeared in the epidermis and the cortex of the PM and TZ. In contrast, 30 min of hyperosmotic stress reduced the pTTL1::GUS signal and only PCZ restored pTTL1::GUS signal to the intensity of control conditions.

\section{Conclusions}

In summary, in this work we used atomic force microscopy to identify a role of TTL1 in the control of cell wall integrity during root anisotropic growth and found a genetic 
interaction between TTL1 and CESA6. In addition, we found that during osmotic stress, anisotropic growth is the first limiting process to establish root growth rate adaptation.

Moreover, the temporary suppression of TTL1 expression and BR pathway in response to osmotic stress and the response to BR treatment together with the evidence of in vivo interaction of TTL3 with most of the BR signaling components [33] suggests a role for TTL1 mediating root growth adaptation to osmotic stress through auxin/BR homeostasis (Figure 9).

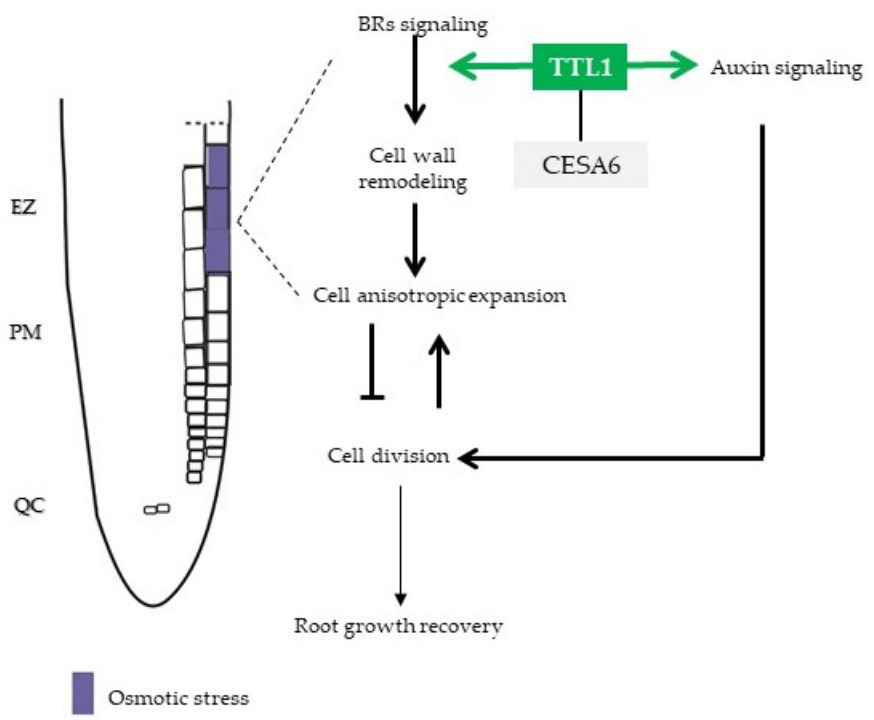

Figure 9. Model that illustrates a scenario for primary root growth recovery during osmotic stress. Osmotic stress is perceived in epidermal cells of EZ and integrates through TTL1 in the BR/auxin signaling pathway that regulates balanced root growth. TTL1 maintain cell wall integrity to sustain cell anisotropic expansion necessary to continuous primary root growth. EZ: Elongation Zone; PM: Proximal Meristem; QC: Quiescent Center; BR: brassinosteroid.

Supplementary Materials: The following are available online at https:/ / www.mdpi.com/2073-442 5/12/2/236/s1. Table S1: Time dependence of Col-0 primary root response to osmotic stress. Table S2: Time dependence of $t t l 1$ primary root response to osmotic stress. Table S3: Time dependence of Col- 0 and $t t l 1$ primary root response to osmotic stress. Table S4: $p$ values for $t$-Test comparison of AEM in Col-0, ttl1, prc1-1, ttl1 prc1-1 grown in control and -1.2 MPa osmotic potential for data in Tables 1 and 2 of the main text. Table S5: Cortical cell number in the PM and Mature cortical cell length meassured in control conditions. Table S6: Cortical cell number in the PM and Mature cortical cell length meassured at $-0.7 \mathrm{MPa}$. Table S7: Cortical cell number in the PM and Mature cortical cell length meassured at $-1.2 \mathrm{MPa}$. Table S8: Root length of Col-0 and $t t l 1$ after 9 days of growth in medium with, $0.2 \mu \mathrm{M}$ of BL, $0.5 \mu \mathrm{M}$ of PCZ, without or with supplementation of $400 \mathrm{mM}$. Figure S1: Force curves and apparent elastic modulus (AEM) of cell walls of epidermal cells in the EZ of Col- 0 and $t t l 1$ roots grown in control conditions. Figure S2: Force curves and apparent elastic modulus (AEM) of cell walls of epidermal cells in the EZ of Col-0 and $t+l 1$ roots grown under osmotic stress. Figure S3: The ttl1prc1-1 mutant exhibits greater reduction of root growth rate than Col-0 in response to increasing osmotic potential. Figure S4: Histogram of Young's modulus obtained from force curves on 9 different cells of three different plants of the ttl1prc1-1 double mutant. Figure S5: Cell size in the PM and EZ determined in control conditions for Col-0 and $t+l 1$ mutant. Figure S6: pTTL1::GUS signal in response to different time of osmotic stress $(-1.2 \mathrm{MPa})$.

Author Contributions: M.S.-S. designed the research. M.B.C.-P. performed root growth experiments. I.R. and M.S.-S. performed Atomic force microscopy experiments. I.R. analyzed atomic force microscopy data. M.S.-S. wrote the manuscript. M.M.S., O.B., V.A.-S. and M.A.B. critical reviewed the manuscript and generated material for this study. All authors have read and agreed to the published version of the manuscript. 
Funding: This research was funded by CSIC I+D 2018, grant No. 95 to M.S.-S.; CSIC Grupos (O.B.) and PEDECIBA. This work was supported by the Ministerio de Economía y Competitividad, co-financed by the European Regional Development Fund (grant BIO2017-82609-R to M.A.B). We received fellowship of ANII and CAP, UdelaR.

Institutional Review Board Statement: Not applicable.

Informed Consent Statement: Not applicable.

Data Availability Statement: The data presented in this study are available in the article or supplementary materials.

Acknowledgments: We thank to Zhi-Yong Wang for 35S::BZR1::YFP seeds. We thanks to Gastón Quero for root growth rate estimations.

Conflicts of Interest: The authors declare no conflict of interest.

$\begin{array}{ll}\text { Abbreviations } \\ \text { RAM } & \text { root apical meristem } \\ \text { SCN } & \text { stem cell niche } \\ \text { QC } & \text { quiescent center } \\ \text { PM } & \text { proximal meristem } \\ \text { EZ } & \text { elongation zone } \\ \text { TZ } & \text { transition zone } \\ \text { DZ } & \text { differentiation zone } \\ \text { GFP } & \text { green fluorescent protein } \\ \text { YFP } & \text { yellow fluorescent protein } \\ \text { GUS } & \beta \text {-glucuronidase } \\ \text { MPa } & \text { MegaPascal } \\ \text { NaCl } & \text { sodium chloride } \\ \text { ABA } & \text { abscisic acid } \\ \text { BR } & \text { brassinosteroid } \\ \text { BL } & \text { epibrasinolide } \\ \text { PCZ } & \text { propiconazole } \\ \text { AFM } & \text { atomic force microscopy } \\ \text { AEM } & \text { Young's Modulus }\end{array}$

\section{References}

1. Monshausen, G.B.; Gilroy, S. The Exploring Root-Root Growth Responses to Local Environmental Conditions. Curr. Opin. Plant Biol. 2009, 12, 766-772. [CrossRef] [PubMed]

2. Sharp, R.E.; Poroyko, V.; Hejlek, L.G.; Spollen, W.G.; Springer, G.K.; Bohnert, H.J.; Nguyen, H.T. Root Growth Maintenance during Water Deficits: Physiology to Functional Genomics*. J. Exp. Bot. 2004, 55, 2343-2351. [CrossRef] [PubMed]

3. Rao, X.; Dixon, R.A. Brassinosteroid Mediated Cell Wall Remodeling in Grasses under Abiotic Stress. Front. Plant Sci. 2017, 8. [CrossRef] [PubMed]

4. Gupta, A.; Rico-Medina, A.; Caño-Delgado, A.I. The Physiology of Plant Responses to Drought. Science 2020, 368, 266-269. [CrossRef]

5. Pandey, B.K.; Huang, G.; Bhosale, R.; Hartman, S.; Sturrock, C.J.; Jose, L.; Martin, O.C.; Karady, M.; Voesenek, L.A.C.J.; Ljung, K.; et al. Plant Roots Sense Soil Compaction through Restricted Ethylene Diffusion. Science 2021, 371, 276-280. [CrossRef]

6. Scheres, B.; Benfey, P.; Dolan, L. Root Development. Arab. Book 2002, 1, e0101. [CrossRef]

7. Verbelen, J.-P.; De Cnodder, T.; Le, J.; Vissenberg, K.; Baluška, F. The Root Apex of Arabidopsis Thaliana Consists of Four Distinct Zones of Growth Activities. Plant Signal. Behav. 2006, 1, 296-304. [CrossRef]

8. Cederholm, H.M.; Iyer-Pascuzzi, A.S.; Benfey, P.N. Patterning the Primary Root in Arabidopsis. Wiley Interdiscip. Rev. Dev. Biol. 2012, 1, 675-691. [CrossRef]

9. Petricka, J.J.; Winter, C.M.; Benfey, P.N. Control of Arabidopsis Root Development. Annu. Rev. Plant Biol. 2012, 63, 563-590. [CrossRef]

10. Pavelescu, I.; Vilarrasa-Blasi, J.; Planas-Riverola, A.; González-García, M.; Caño-Delgado, A.I.; Ibañes, M. A Sizer Model for Cell Differentiation in Arabidopsis Thaliana Root Growth. Mol. Syst. Biol. 2018, 14. [CrossRef]

11. Moubayidin, L.; DiMambro, R.; Sozzani, R.; Pacifici, E.; Salvi, E.; Terpstra, I.; Bao, D.; van Dijken, A.; DelloIoio, R.; Perilli, S.; et al. Spatial Coordination between Stem Cell Activity and Cell Differentiation in the Root Meristem. Dev. Cell 2013, 26, 405-415. [CrossRef] [PubMed] 
12. Chaiwanon, J.; Wang, W.; Zhu, J.Y.; Oh, E.; Wang, Z.Y. Information Integration and Communication in Plant Growth Regulation. Cell 2016, 164, 1257-1268. [CrossRef]

13. González-García, M.P.; Vilarrasa-Blasi, J.; Zhiponova, M.; Divol, F.; Mora-García, S.; Russinova, E.; Caño-Delgado, A.I. Brassinosteroids Control Meristem Size by Promoting Cell Cycle Progression in Arabidopsis Roots. Development 2011, 138, 849-859. [CrossRef] [PubMed]

14. Hacham, Y.; Holland, N.; Butterfield, C.; Ubeda-tomas, S.; Bennett, M.J. Brassinosteroid Perception in the Epidermis Controls Root Meristem Size. Development 2011, 138, 839-848. [CrossRef]

15. Geng, Y.; Wu, R.; Wee, C.W.; Xie, F.; Wei, X.; Chan, P.M.Y.; Tham, C.; Duan, L.; Dinneny, J.R. A Spatio-Temporal Understanding of Growth Regulation during the Salt Stress Response in Arabidopsis. Plant Cell 2013, 25, 2132-2154. [CrossRef]

16. Vilarrasa-Blasi, J.; González-García, M.-P.; Frigola, D.; Fàbregas, N.; Alexiou, K.G.; López-Bigas, N.; Rivas, S.; Jauneau, A.; Lohmann, J.U.; Benfey, P.N.; et al. Regulation of Plant Stem Cell Quiescence by a Brassinosteroid Signaling Module. Dev. Cell 2014, 30, 36-47. [CrossRef]

17. Chaiwanon, J.; Wang, Z.-Y. Spatiotemporal Brassinosteroid Signaling and Antagonism with Auxin Pattern Stem Cell Dynamics in Arabidopsis Roots. Curr. Biol. 2015, 25, 1031-1042. [CrossRef]

18. Vragović, K.; Sela, A.; Friedlander-Shani, L.; Fridman, Y.; Hacham, Y.; Holland, N.; Bartom, E.; Mockler, T.C.; Savaldi-Goldstein, S. Translatome Analyses Capture of Opposing Tissue-Specific Brassinosteroid Signals Orchestrating Root Meristem Differentiation. Proc. Natl. Acad. Sci. USA 2015, 112, 923-928. [CrossRef]

19. Takatsuka, H.; Umeda, M. Hormonal Control of Cell Division and Elongation along Differentiation Trajectories in Roots. J. Exp. Bot. 2014, 65, 2633-2643. [CrossRef] [PubMed]

20. Kong, X.; Liu, G.; Liu, J.; Ding, Z. The Root Transition Zone: A Hot Spot for Signal Crosstalk. Trends Plant Sci. 2018, 23, 403-409. [CrossRef] [PubMed]

21. Feng, W.; Lindner, H.; Robbins, N.E.; Dinneny, J.R. Growing Out of Stress: The Role of Cell- and Organ-Scale Growth Control in Plant Water-Stress Responses. Plant Cell 2016, 28, 1769-1782. [CrossRef]

22. Feng, W.; Kita, D.; Peaucelle, A.; Cartwright, H.N.; Doan, V.; Duan, Q.; Liu, M.C.; Maman, J.; Steinhorst, L.; Schmitz-Thom, I.; et al. The FERONIA Receptor Kinase Maintains Cell-Wall Integrity during Salt Stress through Ca2+ Signaling. Curr. Biol. 2018, 28, 666-675.e5. [CrossRef]

23. Cajero-Sanchez, W.; Aceves-Garcia, P.; Fernández-Marcos, M.; Gutiérrez, C.; Rosas, U.; García-Ponce, B.; Álvarez-Buylla, E.R.; Sánchez, M.D.; Garay-Arroyo, A. Natural Root Cellular Variation in Responses to Osmotic Stress in Arabidopsis Thaliana Accessions. Genes 2019, 10, 983. [CrossRef]

24. Caño-Delgado, A.I.; Metzlaff, K.; Bevan, M.W. The Eli1 Mutation Reveals a Link between Cell Expansion and Secondary Cell Wall Formation in Arabidopsis Thaliana. Development 2000, 127, 3395-3405.

25. Baskin, T.I. Anisotropic Expansion of the Plant Cell Wall. Annu. Rev. Cell Dev. Biol. 2005, 21, 203-222. [CrossRef]

26. Desprez, T.; Juraniec, M.; Crowell, E.F.; Jouy, H.; Pochylova, Z.; Parcy, F.; Hofte, H.; Gonneau, M.; Vernhettes, S. Organization of Cellulose Synthase Complexes Involved in Primary Cell Wall Synthesis in Arabidopsis Thaliana. Proc. Natl. Acad. Sci. USA 2007, 104, 15572-15577. [CrossRef]

27. Crowell, E.F.; Gonneau, M.; Vernhettes, S. Regulation of Anisotropic Cell Expansion in Higher Plants. Comptes Rendus Biol. 2010, 333, 320-324. [CrossRef] [PubMed]

28. Li, S.; Bashline, L.; Lei, L.; Gu, Y. Cellulose Synthesis and Its Regulation. Arab. Book 2014, 12, e0169. [CrossRef] [PubMed]

29. Shi, H.; Kim, Y.; Guo, Y.; Stevenson, B.; Zhu, J.K. The Arabidopsis SOS5 Locus Encodes a Putative Cell Surface Adhesion Protein and Is Required for Normal Cell Expansion. Plant Cell 2003, 15, 19-32. [CrossRef] [PubMed]

30. Xu, S.-L.; Rahman, A.; Baskin, T.I.; Kieber, J.J. Two Leucine-Rich Repeat Receptor Kinases Mediate Signaling, Linking Cell Wall Biosynthesis and ACC Synthase in Arabidopsis. Plant Cell Online 2008, 20, 3065-3079. [CrossRef]

31. Rosado, A.; Schapire, A.L.; Bressan, R.A.; Harfouche, A.L.; Hasegawa, P.M.; Valpuesta, V.; Botella, M.A. The Arabidopsis Tetratricopeptide Repeat-Containing Protein TTL1 Is Required for Osmotic Stress Responses and Abscisic Acid Sensitivity. Plant Physiol. 2006, 142, 1113-1126. [CrossRef]

32. Lakhssassi, N.; Doblas, V.G.; Rosado, A.; del Valle, A.E.; Pose, D.; Jimenez, A.J.; Castillo, A.G.; Valpuesta, V.; Borsani, O.; Botella, M.A. The Arabidopsis TETRATRICOPEPTIDE THIOREDOXIN-LIKE Gene Family Is Required for Osmotic Stress Tolerance and Male Sporogenesis. Plant Physiol. 2012, 158, 1252-1266. [CrossRef] [PubMed]

33. Amorim-Silva, V.; García-Moreno, Á.; Castillo, A.G.; Lakhssassi, N.; Del Valle, A.E.; Pérez-Sancho, J.; Li, Y.; Posé, D.; PérezRodriguez, J.; Lin, J.; et al. TTL Proteins Scaffold Brassinosteroid Signaling Components at the Plasma Membrane to Optimize Signal Transduction in Arabidopsis. Plant Cell 2019, 31, 1807-1828. [CrossRef]

34. Desnos, T.; Orbović, V.; Bellini, C.; Kronenberger, J.; Caboche, M.; Traas, J.; Höfte, H. Procuste1 Mutants Identify Two Distinct Genetic Pathways Controlling Hypocotyl Cell Elongation, Respectively in Dark- and Light-Grown Arabidopsis Seedlings. Development 1996, 122, 683-693.

35. Fagard, M.; Desnos, T.; Desprez, T.; Goubet, F.; Refregier, G.; Mouille, G.; McCann, M.; Rayon, C.; Vernhettes, S.; Höfte, H. Procuste1 Encodes a Cellulose Synthase Required for Normal Cell Elongation Specifically in Roots and Dark-Grown Hypocotyls of Arabidopsis. Plant Cell 2000, 12, 2409-2423. [CrossRef]

36. Murashige, T.; Skoog, F. A Revised Medium for Rapid Growth and Bio Assays with Tobacco Tissue Cultures. Physiol. Plant. 1962, 15, 473-497. [CrossRef] 
37. Anderson, L. Hoyer's Solution as a Rapid Permanent Mounting Medium for Bryophytes. Bryologist 1954, 57, 242-244. [CrossRef]

38. Perilli, S.; Sabatini, S. Analysis of Root Meristem Size Development. Methods Mol. Biol. 2010, 655, 177-187. [CrossRef] [PubMed]

39. Cole, R.A.; McInally, S.A.; Fowler, J.E. Developmentally Distinct Activities of the Exocyst Enable Rapid Cell Elongation and Determine Meristem Size during Primary Root Growth in Arabidopsis. BMC Plant Biol. 2014, 14. [CrossRef]

40. Benech, J.C.; Benech, N.; Zambrana, A.I.; Rauschert, I.; Bervejillo, V.; Oddone, N.; Damián, J.P. Diabetes Increases Stiffness of Live Cardiomyocytes Measured by Atomic Force Microscopy Nanoindentation. Am. J. Physiol. Physiol. 2014, 307, C910-C919. [CrossRef]

41. Sirghi, L.; Ponti, J.; Broggi, F.; Rossi, F. Probing Elasticity and Adhesion of Live Cells by Atomic Force Microscopy Indentation. Eur. Biophys. J. 2008, 37, 935-945. [CrossRef]

42. Segrè, D.; DeLuna, A.; Church, G.M.; Kishony, R. Modular Epistasis in Yeast Metabolism. Nat. Genet. 2005, 37, 77-83. [CrossRef] [PubMed]

43. Baskin, T.I. Patterns of Root Growth Acclimation: Constant Processes, Changing Boundaries. WIREs Dev. Biol. 2013, 2, 65-73. [CrossRef] [PubMed]

44. Winter, D.; Vinegar, B.; Nahal, H.; Ammar, R.; Wilson, G.V.; Provart, N.J. An “Electronic Fluorescent Pictograph” Browser for Exploring and Analyzing Large-Scale Biological Data Sets. PLoS ONE 2007, 2, e718. [CrossRef]

45. Brady, S.M.; Orlando, D.A.; Lee, J.Y.; Wang, J.Y.; Koch, J.; Dinneny, J.R.; Mace, D.; Ohler, U.; Benfey, P.N. A High-Resolution Root Spatiotemporal Map Reveals Dominant Expression Patterns. Science 2007, 318, 801-806. [CrossRef]

46. Cartwright, D.A.; Brady, S.M.; Orlando, D.A.; Sturmfels, B.; Benfey, P.N. Reconstructing Spatiotemporal Gene Expression Data from Partial Observations. Bioinformatics 2009, 25, 2581-2587. [CrossRef]

47. Ulmasov, T.; Murfett, J.; Hagen, G.; Guilfoyle, T.J. Creation of a Highly Active Synthetic AuxRE. Society 1997, 9, $1963-1971$.

48. Clouse, S.D.; Langford, M.; McMorris, T.C. A Brassinosteroid-Insensitive Mutant in Arabidopsis Thaliana Exhibits Multiple Defects in Growth and Development. Plant Physiol. 1996, 111, 671-678. [CrossRef] [PubMed]

49. Hartwig, T.; Corvalan, C.; Best, N.B.; Budka, J.S.; Zhu, J.-Y.; Choe, S.; Schulz, B. Propiconazole Is a Specific and Accessible Brassinosteroid (BR) Biosynthesis Inhibitor for Arabidopsis and Maize. PLoS ONE 2012, 7, e36625. [CrossRef]

50. Wang, R.; Liu, M.; Yuan, M.; Oses-Prieto, J.A.; Cai, X.; Sun, Y.; Burlingame, A.L.; Wang, Z.-Y.; Tang, W. The BrassinosteroidActivated BRI1 Receptor Kinase Is Switched off by Dephosphorylation Mediated by Cytoplasm-Localized PP2A B' Subunits. Mol. Plant 2016, 9, 148-157. [CrossRef]

51. Gou, X.; Yin, H.; He, K.; Du, J.; Yi, J.; Xu, S.; Lin, H.; Clouse, S.D.; Li, J. Genetic Evidence for an Indispensable Role of Somatic Embryogenesis Receptor Kinases in Brassinosteroid Signaling. PLoS Genet. 2012, 8, e1002452. [CrossRef] [PubMed]

52. Lin, W.; Lu, D.; Gao, X.; Jiang, S.; Ma, X.; Wang, Z.; Mengiste, T.; He, P.; Shan, L. Inverse Modulation of Plant Immune and Brassinosteroid Signaling Pathways by the Receptor-like Cytoplasmic Kinase BIK1. Proc. Natl. Acad. Sci. USA 2013, 110, 12114-12119. [CrossRef]

53. Tanaka, K.; Asami, T.; Yoshida, S.; Nakamura, Y.; Matsuo, T.; Okamoto, S. Brassinosteroid Homeostasis in Arabidopsis Is Ensured by Feedback Expressions of Multiple Genes Involved in Its Metabolism. Plant Physiol. 2005, 138, 1117-1125. [CrossRef] [PubMed]

54. Chung, Y.; Choe, S. The Regulation of Brassinosteroid Biosynthesis in Arabidopsis. Crit. Rev. Plant Sci. 2013, 32, 396-410. [CrossRef]

55. Vriet, C.; Russinova, E.; Reuzeau, C. From Squalene to Brassinolide: The Steroid Metabolic and Signaling Pathways across the Plant Kingdom. Mol. Plant 2013, 6, 1738-1757. [CrossRef]

56. Robbins, N.E.; Dinneny, J.R. Growth Is Required for Perception of Water Availability to Pattern Root Branches in Plants. Proc. Natl. Acad. Sci. USA 2018, 115, E822-E831. [CrossRef] [PubMed]

57. Rui, Y.; Dinneny, J.R. A Wall with Integrity: Surveillance and Maintenance of the Plant Cell Wall under Stress. New Phytol. 2019, 225, 1428-1439. [CrossRef]

58. Maurel, C.; Nacry, P. Root Architecture and Hydraulics Converge for Acclimation to Changing Water Availability. Nat. Plants 2020, 6, 744-749. [CrossRef]

59. Ramachandran, P.; Augstein, F.; Nguyen, V.; Carlsbecker, A. Coping With Water Limitation: Hormones That Modify Plant Root Xylem Development. Front. Plant Sci. 2020, 11, 570. [CrossRef]

60. Takahashi, F.; Suzuki, T.; Osakabe, Y.; Betsuyaku, S.; Kondo, Y.; Dohmae, N.; Fukuda, H.; Yamaguchi-Shinozaki, K.; Shinozaki, K. A Small Peptide Modulates Stomatal Control via Abscisic Acid in Long-Distance Signalling. Nature 2018, 556, 235-238. [CrossRef]

61. Nolan, T.M.; Vukašinović, N.; Liu, D.; Russinova, E.; Yin, Y. Brassinosteroids: Multidimensional Regulators of Plant Growth, Development, and Stress Responses. Plant Cell 2020, 32, 295-318. [CrossRef]

62. Planas-Riverola, A.; Gupta, A.; Betegón-Putze, I.; Bosch, N.; Ibañes, M.; Caño-Delgado, A.I. Brassinosteroid Signaling in Plant Development and Adaptation to Stress. Development 2019, 146, dev151894. [CrossRef]

63. Fàbregas, N.; Lozano-Elena, F.; Blasco-Escámez, D.; Tohge, T.; Martínez-Andújar, C.; Albacete, A.; Osorio, S.; Bustamante, M.; Riechmann, J.L.; Nomura, T.; et al. Overexpression of the Vascular Brassinosteroid Receptor BRL3 Confers Drought Resistance without Penalizing Plant Growth. Nat. Commun. 2018, 9, 4680. [CrossRef]

64. Ogura, T.; Goeschl, C.; Filiault, D.; Mirea, M.; Slovak, R.; Wolhrab, B.; Satbhai, S.B.; Busch, W. Root System Depth in Arabidopsis Is Shaped by EXOCYST70A3 via the Dynamic Modulation of Auxin Transport. Cell 2019, 178, 400-412.e16. [CrossRef]

65. Dietrich, D.; Pang, L.; Kobayashi, A.; Fozard, J.A.; Boudolf, V.; Bhosale, R.; Antoni, R.; Nguyen, T.; Hiratsuka, S.; Fujii, N.; et al. Root Hydrotropism Is Controlled via a Cortex-Specific Growth Mechanism. Nat. Plants 2017, 3, 17057. [CrossRef] [PubMed] 
66. Fürst-Jansen, J.M.R.; de Vries, S.; de Vries, J. Evo-Physio: On Stress Responses and the Earliest Land Plants. J. Exp. Bot. 2020, 71, 3254-3269. [CrossRef]

67. Dinneny, J.R.; Long, T.A.; Wang, J.Y.; Jung, J.W.; Mace, D.; Pointer, S.; Barron, C.; Brady, S.M.; Schiefelbein, J.; Benfey, P.N. Cell Identity Mediates the Response of Arabidopsis Roots to Abiotic Stress. Science 2008, 320, 942-945. [CrossRef] [PubMed]

68. Hu, H.; Zhang, R.; Tao, Z.; Li, X.; Li, Y.; Huang, J.; Li, X.; Han, X.; Feng, S.; Zhang, G.; et al. Cellulose Synthase Mutants Distinctively Affect Cell Growth and Cell Wall Integrity for Plant Biomass Production in Arabidopsis. Plant Cell Physiol. 2018, 59, 1144-1157. [CrossRef] [PubMed]

69. Schindelman, G.; Morikami, A.; Jung, J.; Baskin, T.I.; Carpita, N.C.; Derbyshire, P.; McCann, M.C.; Benfey, P.N. COBRA Encodes a Putative GPI-Anchored Protein, Which Is Polarly Localized and Necessary for Oriented Cell Expansion. Arab. Dev. 2001, 15, 1115-1127. [CrossRef]

70. Sampathkumar, A.; Peaucelle, A.; Fujita, M.; Schuster, C.; Persson, S.; Wasteneys, G.O.; Meyerowitz, E.M. Primary Wall Cellulose Synthase Regulates Shoot Apical Meristem Mechanics and Growth. Development 2019, 146, dev179036. [CrossRef] 